\title{
El origen del estado en el Egeo: El ejemplo de Malia en el Minoico Medio IA
}

\author{
Ma Soledad Milán Quiñones de León
}

\begin{abstract}
A comienzos del II Milenio, en una isla del Egeo, Creta, asistimos al nacimiento del primer estado conocido en Europa dando lugar a la denominada civilización minoica. La aparición de una serie de estructuras arquitectónicas de carácter complejo que han sido consideradas como 'palacios' en función del sistema palacial mesopotámico del III Milenio y que han dado lugar a una determinada organización política, social y económica que define a una organización estatal. El ejemplo del palacio de Malia y sus estructuras afines sirve para atestiguar el nacimiento del primer estado europeo. Previo análisis de las diferentes posturas y teorías en torno al origen del estado, se describen las estructuras pertenecientes a los primeros palacios (protopalacial) con el fin de verificar los indicios de una organización estatal centralizada.
\end{abstract}

Palabras clave: Estado-palacio-protopalacial-patio central

At the beginning of the second century, in an Aegean island called Crete, emerged the first European state within what we call the Minoan Civilisation. The evidence of complex architectural buildings named 'palaces' in relation with the Mesopotamian palatial system of the third century implies a specific political, social and economic organisation typical of a state organization. The case of the Mallia palace and its surrounding buildings is a testimony of the emergence of the first European state. After reviewing the different theories on the Origins of the State, we analyse the protopalatial evidences present in Mallia in order to verify the existence of specific features characteristic of a centralised state organisation.

Keywords: State-palace-protopalatial-central courtyard

\section{INTRODUCCIÓN}

En los inicios del II Milenio a.C. asistimos en una isla del Egeo, en concreto en Creta y en el marco de la denominada civilización minoica, al nacimiento del primer estado conocido en suelo europeo. El surgimiento de dicha estructura estatal se manifiesta visiblemente en la aparición de una serie de grandes construcciones que aparecen en la isla en torno al 2000 (MM IA) y que han dado nombre a un cierto tipo de organización política, social y económica que hemos venido denominando como "sistema palacial" por derivación del sistema estatal que surge en Mesopotamia en el III Milenio, donde contamos con estructuras arquitectónicas de similares características. Ciertamente los Estados palaciales del Oriente Próximo e incluso Egipto pueden servir como antecedente y modelo, pero su aplicación al caso cretense presenta numerosas dificulta- des, no sólo de cronologías y desarrollos propios, sino, sobre todo, del hecho de que estamos ante modelos que son muy diferentes entre sí.

Así, a diferencia de Egipto, en Mesopotamia, el avance hacia el nacimiento del Estado fue paulatino y continuo y se inició antes que en Egipto (por ejemplo quinientos años antes que Egipto conozca el metal, ya se emplea en Mesopotamia), la ciudad fue el germen del proceso del surgimiento de la organización estatal en el Próximo Oriente y estas estructuras estatales fragmentadas en pequeñas ciudades se mantuvo largo tiempo (al menos entre c.3400 a 2340). La primera experiencia que tenemos del nacimiento de una sociedad protoestatal que posteriormente dará lugar al nacimiento del Estado, la encontramos en la Baja Mesopotamia, en el centro urbano de Uruk, a finales del IV Milenio (fase de Uruk tardío c.3500-3000 a.C.), "la primera socie- 
dad compleja del antiguo Oriente"(Liverani, 1998:5). En ese lugar y en este período se produce la explosión definitiva de un proceso en el que aparecen concentraciones urbanas de dimensiones impensables con anterioridad (100 ha. de Uruk), con una arquitectura templaria, en especial en el área de Eanna y la aparición de la escritura y, por consiguiente, de una administración sofisticada y personalizada. Por el contrario, lo que caracteriza a Egipto es un comienzo más tardío pero una enorme velocidad en la evolución ${ }^{1}$ de modo que al final prácticamente llega a alcanzar a Mesopotamia en el momento del nacimiento del Estado. Las instituciones fueron también distintas: temprana y rápida imposición de controles políticos sobre una región que comprendía cientos de comunidades caso de Egipto que impide un largo desarrollo de comunidades independientes características del Sumer protodinástico o arcaico (anterior a 2340). Resulta, por tanto, debido a la distancia cronológica y la variedad de modelos y desarrollos, aplicar los procesos que dieron lugar a los estados mesopotámicos y egipcio al caso, cretense, cuestión distinta es que los estados meopotámicos y egipcio, contemporáneos del momento del surgimiento del estado en la isla, y con más de mil años de desarrollo a sus espaldas, contribuyeran al nacimiento de la organización estatal de la civilización cretense.

\section{Teorías sobre el Origen del Estado}

Por otro lado, el origen del Estado ha sido analizado desde diferentes disciplinas: Política, Sociología, Filosofía, Historia y Economía. Dichas investigaciones han ido también ligadas a diferentes escuelas con determinadas líneas de pensamiento (Carneiro, 1970:733-738; Service, 1990; Cohen, Service, 1978) que pueden sintetizarse en dos escuelas principales como ha sido señalado por R. Cohen (Cohen, Service, 1978:5): aquella que defiende las Teorías del Conflicto y aquella que propugna las Teorías de Integración cuyos argumentos básicos, sintetizados en el cuadro siguiente, se contraponen.

\begin{tabular}{|l|l|}
\hline TEORIAS DEL CONFLICTO & TEORÍAS DE INTEGRACIÓN \\
\hline Conflictos Individuales & Circunscripción \\
- Contrato Social & - Barreras geográficas \\
- Darvinismo Social & - Barreras militares \\
Conflicto inter sociedades & \\
- Conquista & Ventajas Organizativas \\
- Selección Natural & - Redistribución \\
Conflicto intra sociedades & - Guerra \\
- Lucha de clases & - Obras Públicas \\
- Lucha de grupos de parentesco & \\
\hline
\end{tabular}

Las Teorías del Conflicto conciben el Estado como una institución que nace para resolver conflictos entre personas o entre grupos, Los sistemas sociales entran en conflicto por motivos diversos (conflictos Inter.-sociedades o externos), por ejemplo, la escasez de recursos, o la posesión de determinados territorios, surgiendo así una competencia entre comunidades o grupos. Uno de estos grupos se constituye en dominante y da lugar a un incremento de las instituciones centralizadas, es decir, a una organización de tipo estatal. Dicha sociedad estatalizada impone su dominio al resto a través de acuerdos ( las teorías del 'contrato social') o hace desaparecer a los otros grupos por conquista o por un

1 "El proceso del Egipto predinástico se parece a una acción química de cambio lento y de reacción final súbita.". proceso de darwinismo social o selección natural en el que solo sobreviven al conflicto, los grupos mejor adaptados y que desarrollan estructuras estatales. Otras teorías defienden el surgiemiento del estado por los conflictos intra-sociedades o internos es decir, no entre sociedades distintas sino en el seno de una sociedad determinada como es el caso de la lucha de clases defendida por el marxismo, o la lucha de sociedades estratificada en grupos de parentesco en lugar de clases sociales.

Las Teorías de Interacción de las que E.R.Service (1990) es uno de sus defensores, postulan que las sociedades son generalmente sistemas

(Wilson, 1953: 65) 
estables que funcionan basados en un amplio consenso de valores. Para esta escuela, el proceso de estratificación social sería coetáneo al de la formación del Estado y no anterior. El Estado, tanto para las teorías del conflicto como para las integrativas es el aparato integrativo de primer orden por encima del nivel de las instituciones de parentesco. Las cuestiones principales se refieren a las causas y la forma en que se realiza esa integración. Mientras que en las teorías del conflicto se produce por la represión de varios tipos, en las teorías de integración, el gobierno ataca la desintegración haciendo otras cosas, llevando a cabo funciones que no van especialmente en contra de la desintegración sino que benefician a la sociedad y, por lo tanto, indirectamente fomentan la integración. Una modalidad de estas teorías son las llamadas de 'circunscripción' ; postulan que las barreras geográficas o militares pueden llevar a la integración y formación de estados , así, por ejemplo, según R.Carneiro, regiones fértiles rodeadas de otras con tierras de mala calidad, como desiertos o montañas improductivas o por el mar, acaban por integrar a estas últimas puesto que ante cualquier tipo de presión o competencia, los habitantes de estas regiones no pueden huir y no les queda otra solución que integrarse. Otro modelo de integración es el que Service denomina teorías de las 'ventajas organizativas': un sistema social organizado produce un efecto integrativo ya que proporciona los medios para ser "intercambiados" por un futuro incierto o menos favorable fuera de esa sociedad. Estas ventajas o beneficios que se obtienen de la organización son los sistemas redistributivos, una buena organización para la guerra y las obras públicas. Un representante de estas teoría sería Karl Wittfogel (1957) y su teoría sobre la irrigación. Su argumento es que la extensión y mantenimiento de un sistema hidráulico extensivo (de riego y control de las inundaciones) presupone una autoridad central. Los sistemas sociales y los controles despóticos de estos sistemas surgen por el desarrollo de un poder burocrático sobre el sistema hidráulico o el control del agua. Esta burocracia al planificar los usos del sistema hidráulico y al emplear mano de obra en su mantenimiento tiene un importante control sobre los medios de subsistencia de la sociedad. Para Service, las teorías de Integración no se excluyen entre sí y sin embargo sí considera que las teorías del Conflicto son demasiado heterogéneas para que puedan darse simultáneamente. Service no defiende las teorías del conflicto basadas en la lucha de clases, puesto que en las sociedades arcaicas y en las de primitivos actuales existe una estratificación entre gobierno y gobernados pero estas diferencias no se basan en riqueza o propiedad o diferentes accesos a los recursos estratégicos, sino que la diferencia entre los dos estratos viene marcada por un poder religioso y político . La vía hacia la civilización la marca el desarrollo de unas burocracias pequeñas y simples formadas por líderes y sus parientes que, bajo unas determinadas condiciones medioambientales, se aprovechan de las grandes potencialidades que proporciona un liderazgo centralizado. Finalmente (Cohen, Service, 1978:49) existen teorías sintéticas que defienden la interrelación de varios procesos a la vez, conflictivos o de interacción.

En mi opinión y siguiendo en parte a R.Cohen (cf.Cohen, Service, 1978:7), ambas posiciones pueden ser válidas. La formación de un Estado surge de la competencia por unos recursos escasos cuando diferentes grupos tienen un acceso desigual a los recursos disponibles. Los estados proporcionan beneficios a sus miembros quienes por su parte están obligados a mantener a una clase dirigente. Está claro que el nacimiento del Estado se produce por una multiplicidad de causas pudiéndose superponer unas a otras: medio físico (localización, condiciones ecológicas), demografía (incremento de población o de densidad), relaciones externas (comercio, guerra, conquistas) y la especialización del trabajo. El salto al Estado, hacia una sociedad más centralizada es el resultado de un incremento de las necesidades de la población y de las funciones que los líderes estaban realizando.

\section{TEORÍAs SOBRE EL ORIGEN DEL ESTADO EN EL EGEO}

C.Renfrew ha analizado el nacimiento del Estado en el Egeo (Renfrew, 1972) y ha propuesto dos modelos alternativos: el modelo de subsistencia-redistribución (efecto multiplicador) y el de la especialización artesanal-riqueza. El modelo de subsistencia-redistribución considera que el crecimiento o desarrollo de una sociedad se ve favorecido por determinadas condiciones que interaccionando entre ellas dan lugar a lo que él denomina el "efecto multiplicador" (por ejemplo el paso de la caza-recolección a la agricultura o la sustitución de herramientas de piedra por las de metal produce un cambio en los patrones de asentamiento). La sociedad es un "sistema" dentro del cual se desarrollan una serie de 'subsistemas ' (cultura, religión, población etc.) de modo que, si se produce una innovación en un subsistema, favorece la innovación en otro y esta interacción entre sistemas es lo que produce un crecimiento sostenido.El "efecto multiplicador" sirve, por tanto, para analizar los orígenes de civilizaciones, entre ellas la egea. La tecnología se desarrolla 
en la producción artesanal de la mano del comercio y de la redistribución. Pero ninguno de estos factores por sí solo pudo ser la causa del nacimiento de una civilización. Solo cuando una innovación en uno de los subsistemas dé lugar al desarrollo de otros por el proceso del "efecto multiplicador" se producirá un crecimiento sostenido. El crecimiento sostenido, los cambios a largo plazo en la cultura humana no se producen a través del progreso social solamente ni por los adelantos tecnológicos independientes sino por la exclusiva habilidad humana de relacionar ambos aspectos. Las condiciones iniciales para la aplicación de este modelo pudieron darse en el Egeo donde, hacia el 4000 se constata la práctica de una agricultura mixta aunque hay pocas evidencias de una especialización artesanal y de la existencia de una jerarquía social. En el sur del Egeo (Myrtos, Lerna y Chalandriani) se observa un incremento de población a través del estudio de los asentamientos y aparecen una serie de evidencias (concentración de bienes para su distribución, uso de sellos y sellantes, edificios de mayor tamaño e indicios de riqueza) sobre las que Renfrew hipotiza que sólo en áreas de producción diversificada (en términos del policultivo mediterráneo de olivo, vid y cereales) puede surgir un sistema redistributivo (Renfrew, 1972:482).

El otro modelo de Renfrew es el de 'especialización artesanal-riqueza' en el que el factor principal para el nacimiento del Estado es el surgimiento de una sociedad estratificada en función de la riqueza material y/o habilidades militares. El sistema productivo debe mantener a una clase artesanal que produzca bienes de prestigio sobre todo en metal dando lugar al incremento de la actividad comercial. Ambos modelos explican el nacimiento de una jerarquía social.

Koehl (Koehl, 1995: 28) rechaza las teorías de Renfrew sobre la organización política y social minoica, sigue el esquema de desarrollo de las comunidades sociales (cazadores recolectores, jefaturas y estatales) de Service y considera que en el Bronce Medio, Creta estaba organizada en jefaturas, sociedades redistributivas en cuyos centros (palacios) se coordina la actividad social, económica y religiosa y estarían gobernadas por un rey o príncipe. De hecho los hallazgos de objetos de prestigio, son sobre todo de tipo cultual (vasos de piedra, cálices) y no aparecen exclusivamente en los palacios sino, además en otros centros relevantes como

2 Aunque el enfoque exógeno puede ser apropiado en aquellos casos donde quede totalmente demostrado una relación de dominación entre una comunidad y otra no es un modelo
Monastiraki, Palaiokastro, etc... Sobre ello quizá se pueda apuntar la existencia de numerosos centros de poder con su propia organización política, religiosa y económica dependiendo o no de un palacio.

Otro enfoque es el_Peer Polity Interaction (PPI) (Renfrew, Cherry, 1986).Por polity se entiende una unidad socio-política autónoma, que llamaremos para simplificar, "comunidad". La PPI recoge toda una serie de interacciones que se producen entre "comunidades" socio-políticas autónomas situadas dentro de la misma región geográfica o, en algunos casos, en áreas más amplias. Este tipo de interacciones pueden ser de varios tipos incluyendo aspectos como imitación/emulación, competencia, guerra, intercambio de bienes o de información . El proceso de cambio en una sociedad puede englobar dos tipos diferenciados, un cambio de tipo exógeno como el formulado las teorías difusionistas o los que presentan los modelos de 'dominación' de unas “comunidades" sobre otras, los conceptos de estado prístino y secundario, o centro y periferia, etc. De todas maneras un enfoque exógeno no parece apropiado para explicar el cambio social en la antigüedad ${ }^{2} \mathrm{El}$ otro tipo de proceso de cambio es el endógeno. Este tipo de enfoque es el que recogen aquellos que buscan explicaciones de tipo 'procesual' que entronca también con los postulantes de la Teoría de Sistemas y sería compatible con el modelo de Renfrew del "efecto multiplicador" (Renfrew, 1972).

El planteamiento de PPI está en medio de estos dos procesos de cambio. Aquí, el cambio surge por la interacción entre las "comunidades" y opera en muchos casos dentro de un nivel regional $y$, aunque es importante tener en cuenta los procesos productivos y los contactos a larga distancia, las interacciones a escala intermedia entre "comunidades" locales independientes son más importantes. Es precisamente en este nivel intermedio donde operan también los procesos de formación étnica y donde pueden asentarse los cimientos para el surgimiento del estado.

En definitiva lo que propone el concepto de PPI es que el proceso de transformación no sólo se lleva a cabo debido a procesos internos que se van intensificando (Teoría de Sistemas), ni como respuesta a un estímulo exterior, sino como el resultado de la interacción entre "comunidades" iguales que podemos analizar bajos aspectos tales como la emulación y competitividad, las representaciones simbólicas, la transmisión de ideas y el incremento en el flujo de

aplicable a todos los casos de la antiguiedad: :"it has the effect of relegating to the wings all the action of the prehistoric drama”. Gordon Childe (1956:154) 
bienes. El enfoque de PPI busca identificar algunos procesos de interacción dentro de todo el área que comprende la civilización minoica, que pudieran dar lugar a esa cultura homogénea y que pueden también ser evidenciados por la arqueología. Creta es desde varios puntos de vista (étnico, lingüístico y cultural) diferente a sus vecinos más próximos incluso antes de la Era palacial y este hecho se ha utilizado como argumento para defender el nacimiento de la civilización palacial como resultado de un desarrollo interno. Si asumimos que estas homologías estructurales y sus transformaciones surgen solamente de la interacción entre las 'comunidades políticas' estamos descartando una posible influencia exterior, por ejemplo, del Oriente Próximo. Sin embargo, a nuestro juicio, los contactos externos merecen ser considerados ya que sin duda pudieron jugar también un papel en el nacimiento de la civilización cretense y están evidenciados. Disponemos de suficientes pruebas e indicios que atestiguan la existencia de intercambios de larga distancia de mercancías de valor entre Creta y el Oriente Próximo a través de toda la época de los Primeros palacios (Watrous, 1987:65-70). No se puede negar la existencia de contactos, aunque sean indirectos, entre Anatolia, Levante y Oriente Próximo con Creta en los últimos siglos del período prepalacial. En el período MA III-MM I A se produce una concentración demográfica en la isla que trae consigo una mayor complejidad en la organización social. La competitividad creciente entre elites emergentes pudo reflejarse en la regionalización progresiva de la cultura de finales de la época prepalacial. Y, parece razonable pensar que la sociedad minoica en el umbral de la era palacial estaba incipientemente estratificada y conocía la naturaleza de la autoridad real y su legitimación en los reinados del Oriente Próximo. El conocimiento de las instituciones y los aparatos estatales del Oriente no causaron el surgimiento de las 'comunidades' de tipo estatal, pero sí provocaron una competencia en la que las elites de las 'comunidades' minoicas vecinas buscan asegurar un estatus mayor entre 'comunidades'. Con el surgimiento de los primeros palacios este comercio a larga distancia se incrementa con el objetivo de intercambiar objetos de prestigio $\mathrm{y}$, dentro del Egeo, se produce en la isla de Creta. Aunque estos palacios son multifuncionales y tienen muchos puntos de similitud con los del Oriente Próximo también presentan otros rasgos que los diferencian como son las características arquitectónicas de tradición local.

Otros modelos aplicados al nacimiento del estado en el Egeo han sido el concepto de'almacenamiento social' (social storage) de Halstead
(Halstead, 1981; O'Shea 1981 y Halstead, O'Shea, 1982: 92-99), que en definitiva, es una variante del modelo de subsistencia/redistribución de Renfrew, siguiendo el concepto de excedente ya utilizado por Childe (el principal motor hacia el urbanismo fue el desarrollo de una producción intensiva de alimentos capaz de sustentar a una mayor población y de proporcionar un "excedente social concentrado" suficiente para sostener una elite jerárquica y a un Estado represivo para mantener su dominación; Childe, 1950:3-17), plantea tres respuestas diferentes ante catástrofes de tipo medioambietal que puedan dar lugar a malas cosechas y, en consecuencia, a una escasez de alimentos. Se trata de la movilidad (ocupación de otras tierras), la diversificación (en la producción de alimentos) y el almacenamiento (del excedente de producción). En el caso de aquellos agricultores sedentarios que han realizado inversiones en la tierra, la movilidad no es una alternativa pero sí la diversificación de la producción. Sin duda, en la antigüedad la diversificación ha sido una opción estratégica clave para mitigar las consecuencias de malas cosechas. Si las situaciones adversas perduran, Halstead plantea la conversión del excedente de producción en objetos de valor que tengan mercado para que, en el caso de malas cosechas, puedan ser intercambiados por productos de subsistencia con aquellas zonas que no estén sufriendo la misma situación, es lo que llama 'almacenamiento social'. En asentamientos con una cierta estratificación social, el 'almacenamiento social' conlleva a una acumulación de riqueza y de poder que podrá dar lugar a sociedades con economías redistributivas como la minoica y micénica.

Por último, Sherrat (1981: 234-245) ha introducido el modelo de la 'revolución de los productos secundarios' que hace hincapié en el origen del Estado como consecuencia de una intensificación y diversificación de los animales domésticos (utilización de animales para tracción, producción de leche y obtención de lana y pieles).

\section{Malia en El MM IA}

Como dijimos, a finales del Bronce Antiguo egeo (ca. 2100-1900 a.C.) surgen en la isla de Creta un conjunto de estructuras arquitectónicas monumentales características que revelan un cambio en las estructuras políticas, económicas y sociales de la isla, se trata de los llamados 'palacios' minoicos cuyo exponente más famoso es el llamado 'Palacio del Rey Minos' y que corresponde al de Cnoso. En dichos palacios se han detectado dos fases claras de construcción, la llamada de los Primeros Palacios o protopalacial (2000-1700 a.C.) y la de los Segundos 
Palacios o epoca Neopalacial (1700-1400 a.C.). Estos Segundos Palacios fueron construidos sobre unas estructuras anteriores (los Primeros Palacios) que fueron derruidas quizá por un terremoto. A la luz de las investigaciones actuales, tenemos claramente atestiguados al menos tres palacios de la época Protopalacial o Primeros Palacios que son los de Cnoso, en el centro norte de la isla, Festo, al sur de la llanura de Mesara y Malia, en el noreste de Creta. Los tres palacios presentan la misma orientación siguiendo dos ejes, norte-sur y este-oeste. La organización del espacio también es idéntica: las habitaciones se aglutinan en torno a un patio central rectangular de grandes dimensiones formando grupos según su funcionalidad. Las fachadas de estos palacios alineadas en relación con el patio están constituidas por entrantes y salientes.Al Este de la isla se encuentra el palacio Zakros pero todavía no está claro que éste cuente con una fase protopalacial. Nosotros nos centraremos en Malia porque el primer palacio de Malia y las estructuras protopalaciales afines (Poursat, 1992), aunque mucho menos conocido por el gran público que el de Cnoso, presentan unas características particulares que constituyen un ejemplo único para poder explicar los cambios que se producen en ese preciso momento en la isla de Creta y que dieron lugar al surgimiento del primer estado europeo a finales del III Milenio a.C.

El antiguo asentamiento de Malia se sitúa junto al mar en la costa septentrional de la isla a unos cuarenta kilómetros al este de la actual capital, Iraklio, sobre una llanura litoral que se extiende al pie de los montes de Selena y de la colina del Profeta Elías.

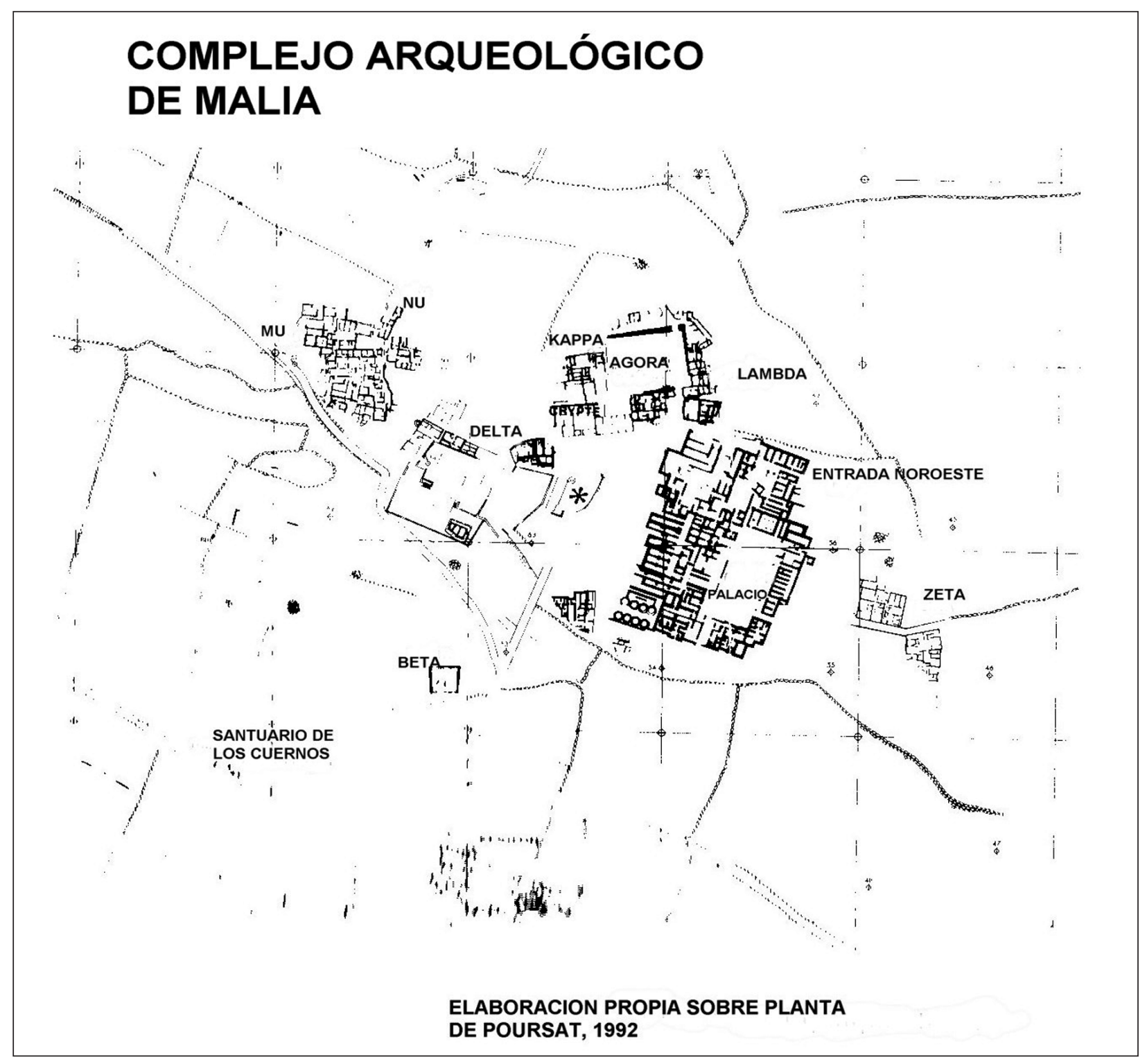

Fig 1.- Complejo arqueológico de Malia 
Las primeras excavaciones en Malia datan de 1915, fueron dirigidas por el arqueólogo griego J. Hatzidakis y continúan en la actualidad a cargo de la Escuela de Arqueología Francesa de Atenas. Estas prolongadas excavaciones han permitido descubrir una serie de estructuras, entre las que cabe señalar: el palacio, parte del caserío urbano, una necrópolis (Chrysolakkos), un ágora, un santuario, la denominada Cripta Hipóstila y el llamado 'Barrio Mu' formado por un conjunto de diferentes ámbitos o áreas dedicadas a la producción artesanal.

Malia fue ocupada a partir del Neolítico y durante los períodos prepalacial, protopalacial y palacial. Hacia 1700 fue totalmente destruida, probablemente a causa de un terremoto. Tras ello, algunos edificios nunca fueron reconstruidos (Barrio $\mathrm{Mu}$ ), otros se reconstruyeron sobre la estructura anterior (palacio) y se erigieron nuevas estructuras (los llamados edificios
Epsilon y Delta). En torno a 1450 a.C., al igual que sucede en los palacios de Festo y Zakro, Malia fue definitivamente destruida y abandonada.

El palacio propiamente dicho se alza sobre una pequeña cima rocosa situada a unos quince metros sobre el nivel del mar en la encrucijada de una red de vías pavimentadas. Posee una longitud de ciento quince metros de norte a sur y de ochenta y siete metros de este a oeste y ocupa un área de $8.900 \mathrm{~m}^{2}$.

La mayor parte de las estructuras actualmente visibles corresponden a la época neopalacial o Segundo palacio mientras que los vestigios protopalaciales o del Primer palacio se encuentran dispersos y parcialmente cubiertos por los estratos del Segundo. No obstante y debido al tema que nos ocupa, describiremos las partes evidenciadas del período protopalacial.

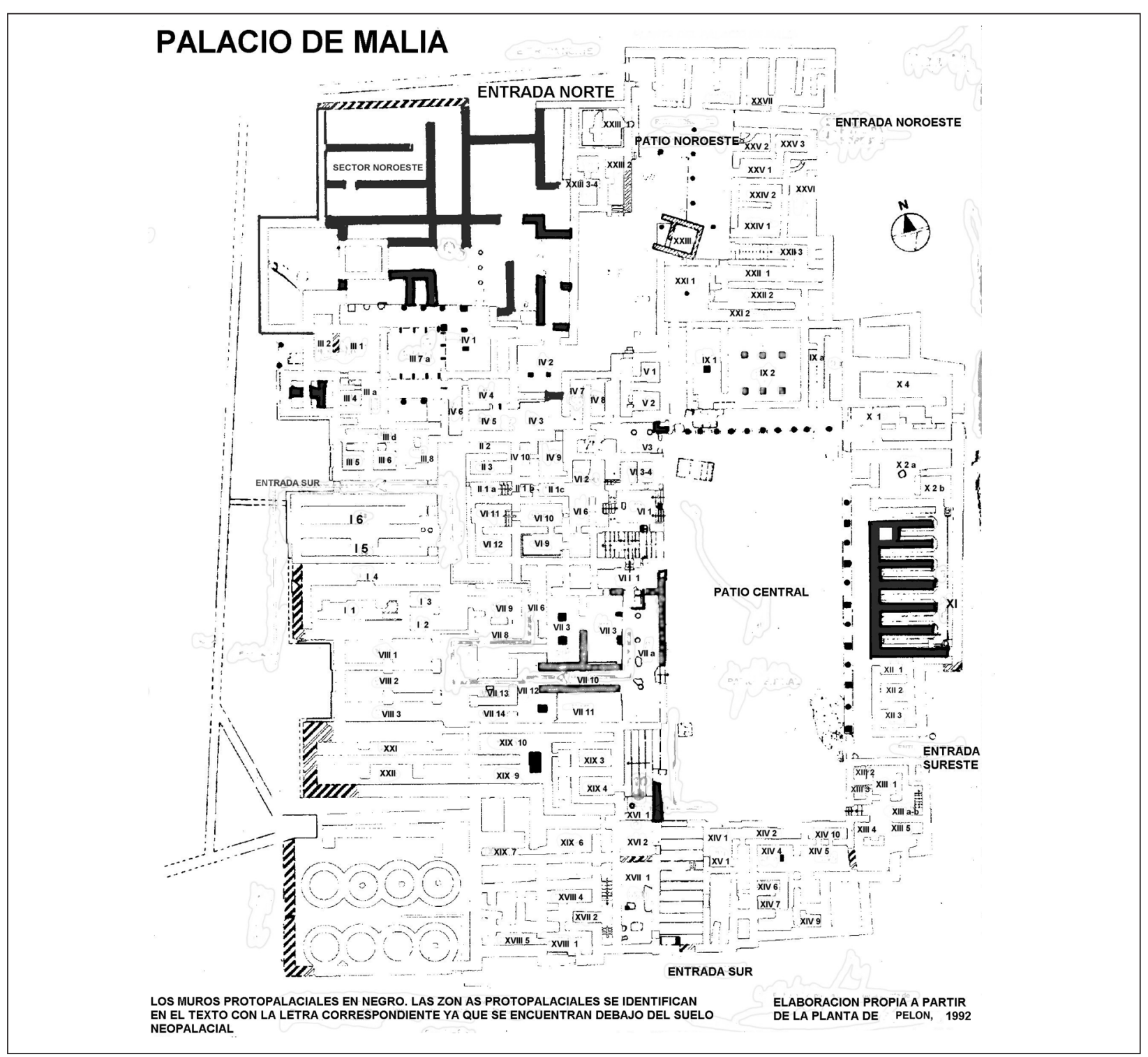

Fig 2.- Planta del Palacio de Malia 
En el noroeste del palacio (justo al norte de la zona de representación del segundo palacio), tenemos una gran extensión (sector noroeste) de muros arrasados. Los muros que aparecen ala vista pertenecen al primer palacio. Justo al borde del patio Oeste hay una serie de estancias alargadas dirección este-oeste que parecen almacenes y que dan hacia un patio que se orienta norte-sur. Hacia el este se identifica claramente un patio porticado con suelo estucado del que quedan además restos de bases de columna.

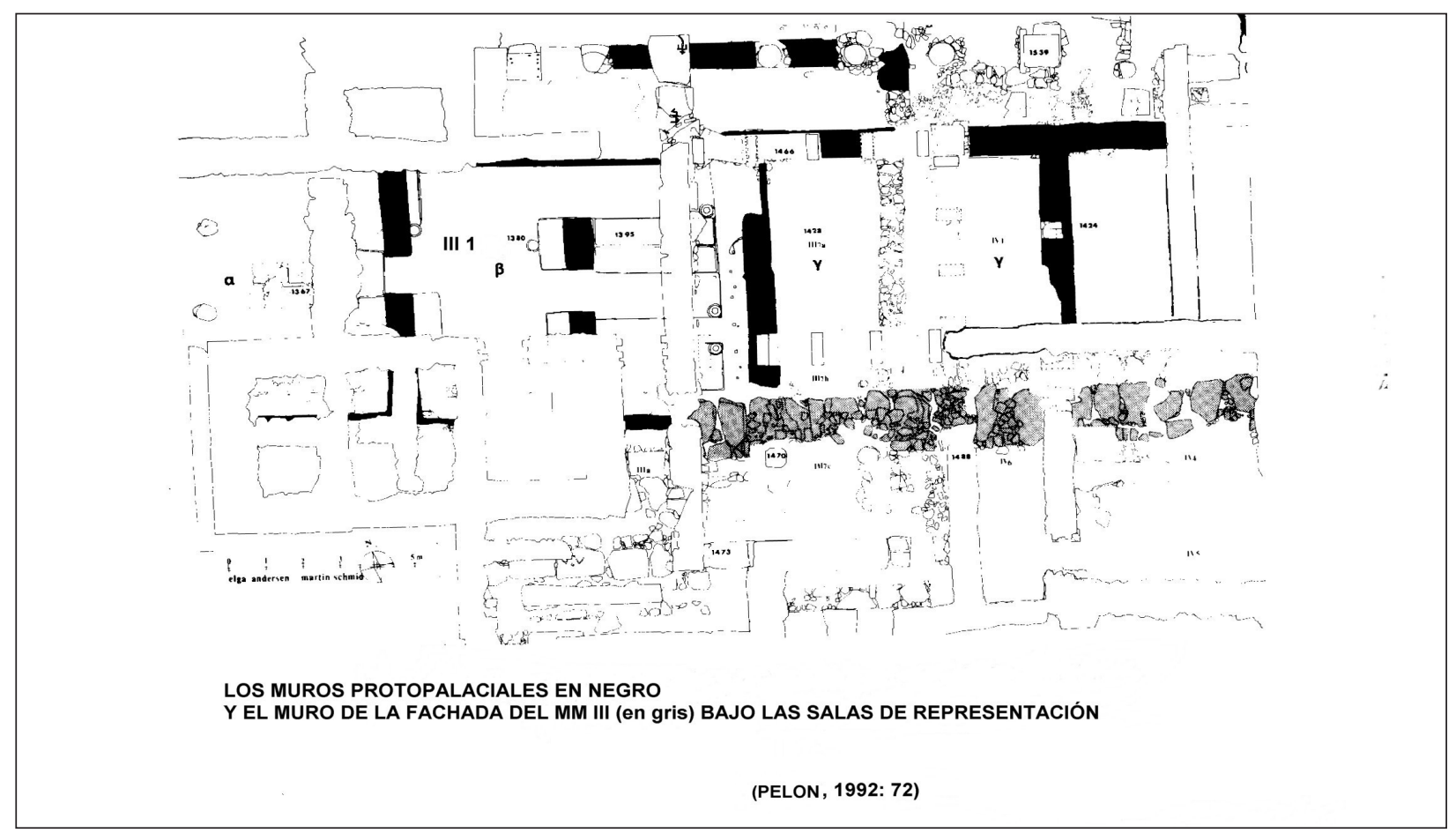

Fig 3.- Zona protopalacial en Negro y del MM III en gris bajo la zona de Representación III.

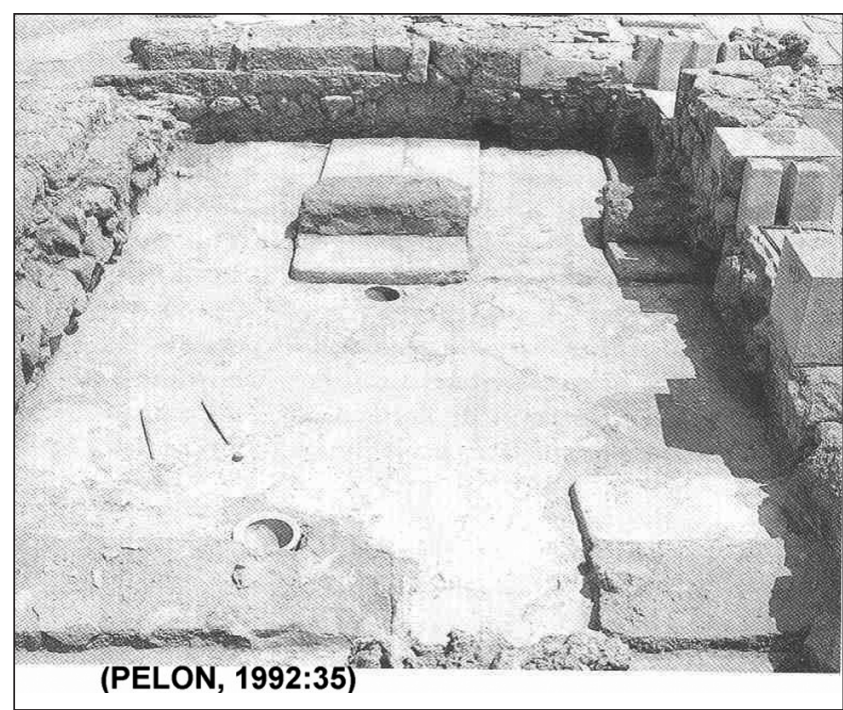

Fig 4.- Sala protopalacial $\beta$, donde aparecieron las dos espadas (bajo la habitación IIII.

3 A pesar de las dudas al respecto (Van Effenterre, 1982), O.Pelon en las excavaciones llevadas a cabo en 1981 ha confirmado esta datación corroborando las excavaciones ante-
Todas estructuras continuarían por debajo de la zona III y IV del segundo palacio. Debajo de la zona III $_{1}$ y III 7 hay unas estructuras bien conservadas del período protopalacial; la sala, (debajo de la III ${ }_{1}$ ) es una estancia de grandes dimensiones (nueve por seis metros) con el suelo totalmente estucado. La pieza está provista de un sistema poco habitual de plataformas, canales y de vasos colectores que son comparables a los de los almacenes de la zona este. En ella aparecieron las dos famosas espadas, una de ellas, la del 'acrobata' con una lama de setenta y dos centímetros de longitud y que llevaba una empuñadura de oro en el que aparece grabada la imagen de un acróbata utilizando la técnica del repujado. Ambas espadas están datadas en el Periodo Protopalacial $^{3}$ y fueron halladas en los escombros procedentes de la destrucción de los primeros palacios en el Minoico Medio II. Este hallazgo es de gran relevancia puesto que constituye una prueba

riores de 1936 y de 1949 (Chapoutier) disipando toda duda al respecto (Pelon, 1982 y 1983) 


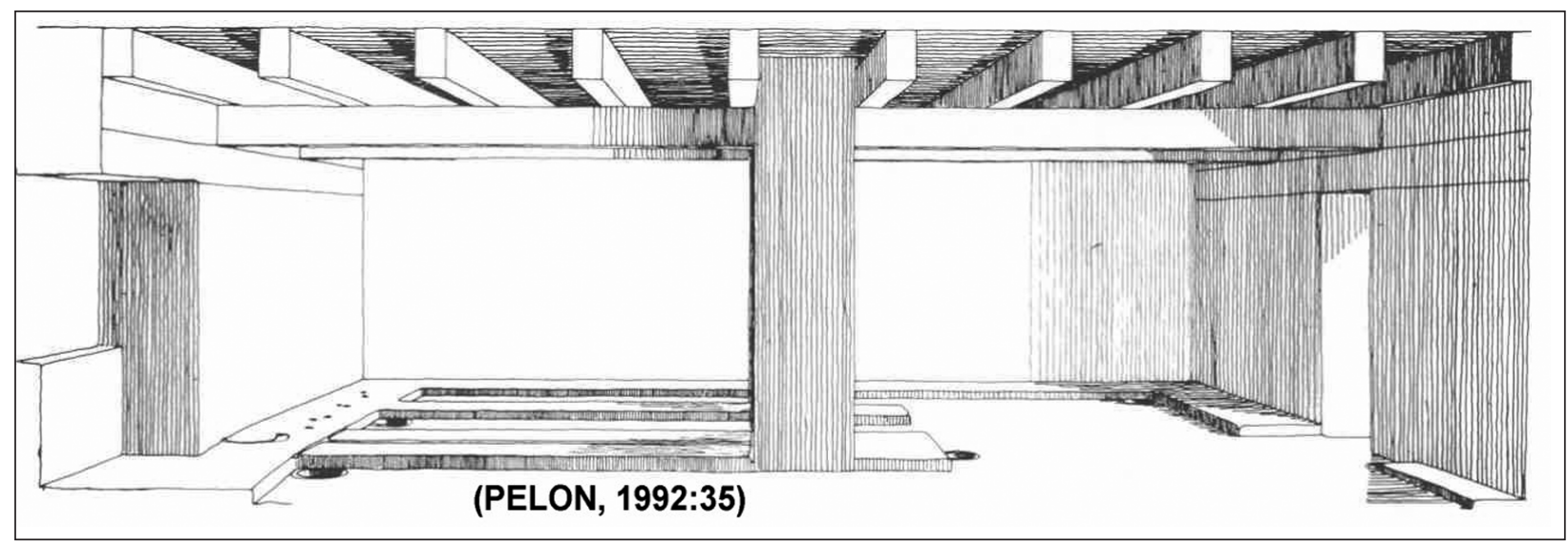

Fig 5.- Reconstrucción sala $\beta$.

del desarrollo de la artesanía minoica con la presencia de orfebres en Malia en este período. En el mismo lugar han aparecido también una veintena de vasos 'de Jamezi', algunos con inscripciones jeroglíficas, una píxide de piedra con tapadera y restos de una figurilla de marfil. Junta a ella se han despejado otras dos estancias protopalaciales, a la más occidental $(\alpha)$, pertenecen las bases de columna hoy visibles delante de la fachada Oeste y podría tratarse de un santuario; la tercera $(\gamma)$ tenía dos huecos para columnas de madera.

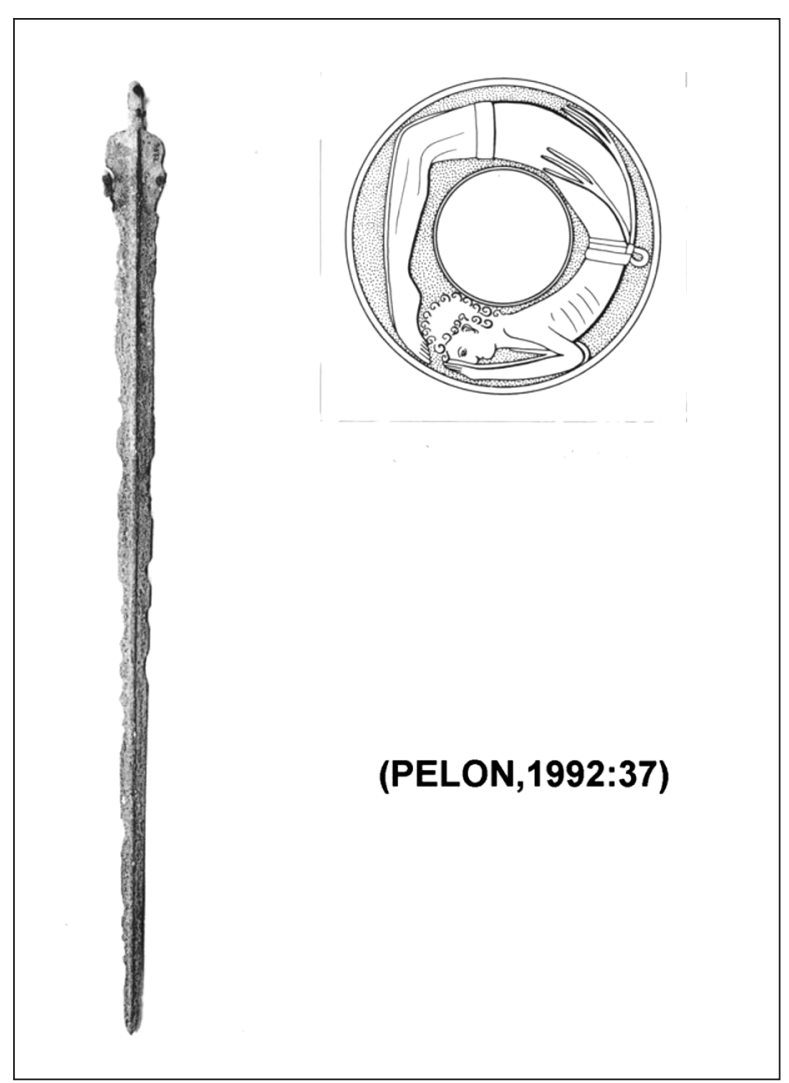

Fig 6.- Dibujo espada del acróbata
En definitiva, estas salas llaman indudablemente la atención por sus dimensiones, por el trabajo empleado en el estucado de los suelos, los muros, el sistema de plataformas que hace pensar en almacenes con algunas características especiales, etc vinculadas quizá con el ámbito religioso. Al período protopalacial pertenece también un gran espacio revestido de kalderim situado en un entrante de la fachada Oeste del Segundo palacio justo en el ángulo Noroeste .

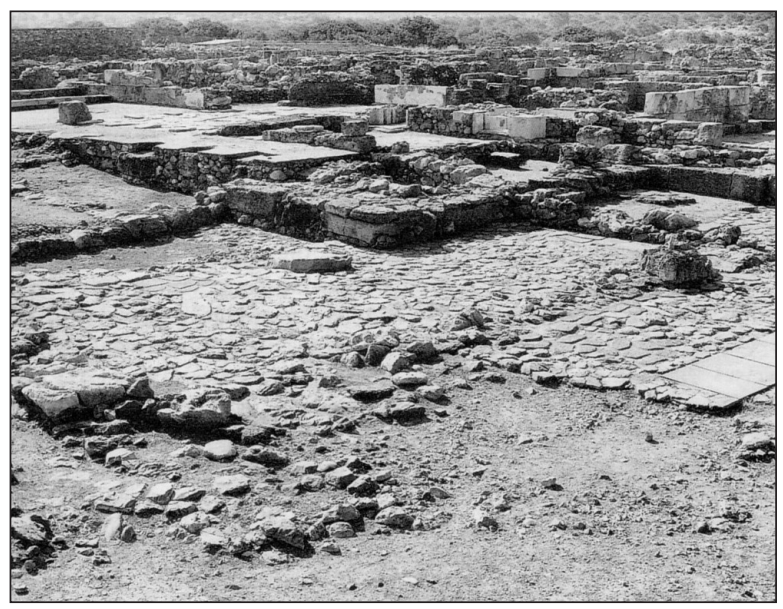

Fig 7.- Zona protopalacial de kalderim (Noroeste visto desde el noroeste). (Pelon, 1992:33)

El patio central, orientado Norte-Sur como los demás palacios minoicos, es un espacio rectangular de cuarenta y ocho por veintidós metros cuyo suelo es de arena pisada y se encuentra pavimentado en algunas zonas. Se han efectuado sondeos en varias partes del patio y se ha descubierto que había cuatro o cinco suelos superpuestos de los cuales los más antiguos datan del Período Protopalacial (Pelon, 1986a:814). El suelo del nivel protopalacial tiene un desagüe cuidadosamente alisado que va dirección norte sur y que ya se había detectado en la zona 
Norte. Asimismo, se ha constatado que la construcción del patio se había efectuado sobre una estructura prepalacial partiendo de la zona IX b (escalera de la Sala Hipóstila al norte del patio central, que se remontaba a la mitad del III milenio -MA IIA(Pelon, 1992:41). También se ha encontrado una estratigrafía del hábitat prepalacial compuesta por tres fases y la más reciente ha producido cerámica flambeada de Vasiliki (Pelon 1986a:814-816).

En el suelo de tierra de la estructura $\mathrm{IV}_{7}$ ha aparecido una especie de cajón de lajas de ammouda (piedra de gres arenoso obtenido al borde del mar de fácil transformación y de color ocre)que contenía un vaso intacto con forma de tetera, que se ha datado en el MA III-MM IA y que podría tratarse de un depósito de fundación en relación con la primera construc-

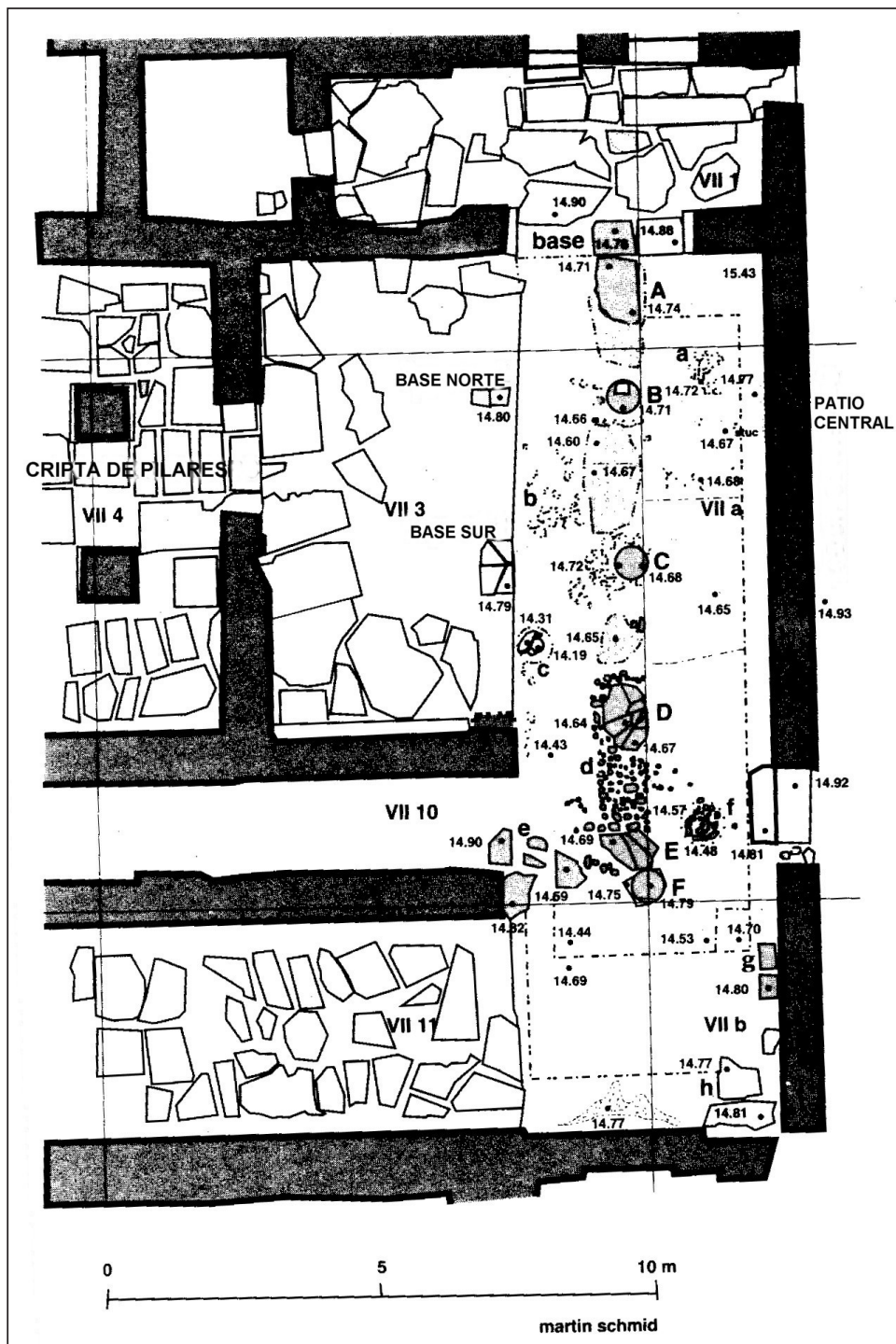

(PELON, 1999: 470) ción palacial (Pelon, 1986b:3-19) Así, la colocación del vaso dentro de una caja de lajas especialmente construida al efecto, su situación en el interior, la conexión con el muro norte-sur contra el que estaba situado ha llevado a pensar que se trata de un depósito de fundación pero ninguno de los encontrados en la Creta minoica reúne estas características.

Como antesala al vestíbulo comentado existe una habitación con alineación norte-sur, paralela al patio central $\left(\mathrm{VII}_{\mathrm{a}}\right)$ y que está atravesada por una columnata interior visible en las bases de columna que se han conservado. Esta estancia inicialmente se había considerado como parte de la $\mathrm{VII}_{3}$ (vestíbulo) considerándola por tanto como una de las mayores del palacio ( 9 por 9,30 metros) pero en 1998 se realizaron nuevos sondeos sobre esta estancia ante la hipotésis de que el nuevo palacio había sido construido con una nueva alineación más hacia el este y se pudo confirmar que el lado Oeste del patio central se había trasladado unos tres metros más hacia el Este transformando el pórtico abierto del Primer palacio en una estancia cubierta. Igualmente, gracias a estas nuevas actuaciones, se ha podido constatar que debajo del primer palacio había ya una estructura prepalacial de la que se ha encontrado un 'probable' depósito de fundación (Pelon, 1999:468-481).

Al Norte de la loggia (nombre que se da a la estancia $\mathrm{VI}_{1}$ del segundo palacio, tiene el suelo enlosado y similar al Salón del Trono del palacio de Cnoso), se disponen dos pequeñas habitaciones ( $\mathrm{VI}_{3-4}$ ) en las que se encontraron unas grandes jarras hundidas en el suelo. Desde esta estancia una pequeña escalera desciende a la habitación VI 2 , donde, al mismo nivel que el patio central, se ha descubierto un doble suelo estucado con lajas de ammouda y una acanaladura del período protopalacial que continúa en la habitación VI $3 . \mathrm{La}$ habitación $\mathrm{VI}_{2}$ está bastante deteriorada y los muros norte y oeste, de adobe, están totalmente derruidos. Esta pieza se conoce como la 'Sala del leopardo' porque en ella se descubrió un mango de esquisto con forma de leopardo junto con una espada con un pomo de cristal, un brazalete de bronce y otras dos armas de bronce. La espada con el pomo de cristal con una lama de más de un metro, tiene una nervadura plana poco habitual; la empuñadura estaba hecha en piedra calcárea gris y recubierta de una lámina de oro; el pomo

Fig 8.- Zona VII (sondeos comentados) 
de cristal de roca está tallado con ocho caras y corresponde al período Protopalacial. Se trata de objetos de carácter 'sagrado' y de representación y Cadogan, ha calificado estancia como 'tesoro religioso' (Cadogan, 1976:114).

Al norte de la estancia $\mathrm{VI}_{2}$, una pequeña habitación sin acceso directo ha sido interpretada como un baño a causa de la presencia de un dispositivo de evacuación de aguas bajo el muro septentrional. En realidad puede ser un pequeño pozo de luz que se empleaba también como desagüe del piso superior. Al oeste de esta misma sala (II 1c), apareció en una serie de piezas estrechas y alargadas un gran pithoi 'de medallones' de $1.55 \mathrm{~m}$ de altura. Justo debajo queda la estructura de un muro protopalacial. Estas estancias, en fila una tras otra, tenían la función de almacenes, ya que en ellas aparecieron varios vasos y jarras. Podría existir un acceso directo desde aquí a los almacenes del Oeste. Al oeste de la loggia, entre dos bases de columna de gran tamaño una escalera con cuatro peldaños desciende hacia la estancia VI 2-6. Desde aquí se accede a varias habitaciones de función indeterminada. Una de ellas (VI 9 ) está totalmente rodeada por un banco corrido mientras que la $\mathrm{VI}_{12}$ podría tener la forma de una piscina lustral .

En la mayor parte de la zona VI se extienden las estructuras del Período Protopalacial a las que se ha podido acceder del suelo por una escalera en la estancia $\mathrm{VI}_{9}$. En estos subterráneos se han hallado las armas de la habitación VI 2 comentadas así como vestigios de un taller de marfil y un sello del MM II de tres caras en las habitaciones $\mathrm{VI}_{9}$ y VI 10 respectivamente.

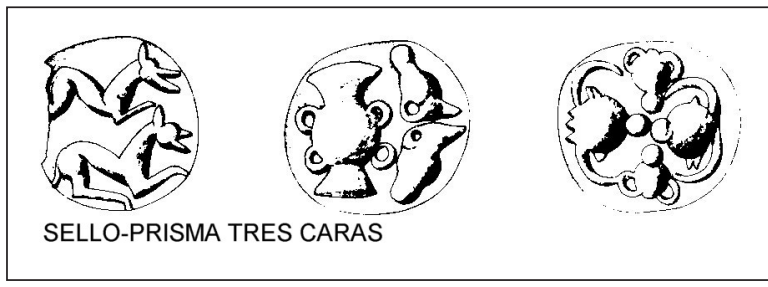

Fig 9.- Dibujo de sello prisma de tres caras encontrado en la habitación VI 9 (Pelon, 1992:60)

Detrás del Pórtico Este (XI) se halla una zona de almacenes compuesta por siete estructuras rectangulares, de 6.50 metros y tres más estrechas de dos metros, perpendiculares a un pasillo que mide más de diecisiete metros de longitud. A lo largo de las paredes de cada almacén quedan unas plataformas laterales estucadas que dejan en medio una pequeña vía de comunicación. Sobre estas plataformas se situaban los vasos de diferente tamaño (desde pequeñas jarras a grandes pithoi). A lo largo de cada banco hay una pequeña canalización para evacuar el líquido que pudiera derramarse de los vasos de almacenamiento. En su extremo se situaba una vasija para recoger los restos de líquido. El pasillo perpendicular contaba también con una plataforma adosada al muro Este exterior del palacio y un canal longitudinal con un vaso colector en el medio. En ambos extremos de la plataforma hay dos elementos interesantes, en el extremo norte una pila de piedra con un bloque monolítico formando un banco que podría servir para triturar grano y en otro extremo una especie de cuba rodeada por un muro de placas verticales cuya utilidad podría ser la de recoger líquidos. Los almacenes descritos se fechan en época protopalacial y continuaron en uso en el período neopalacial. Estas mismas estructuras del período protopalacial están presentes en la Cripta hipóstila y en el Barrio Mu.

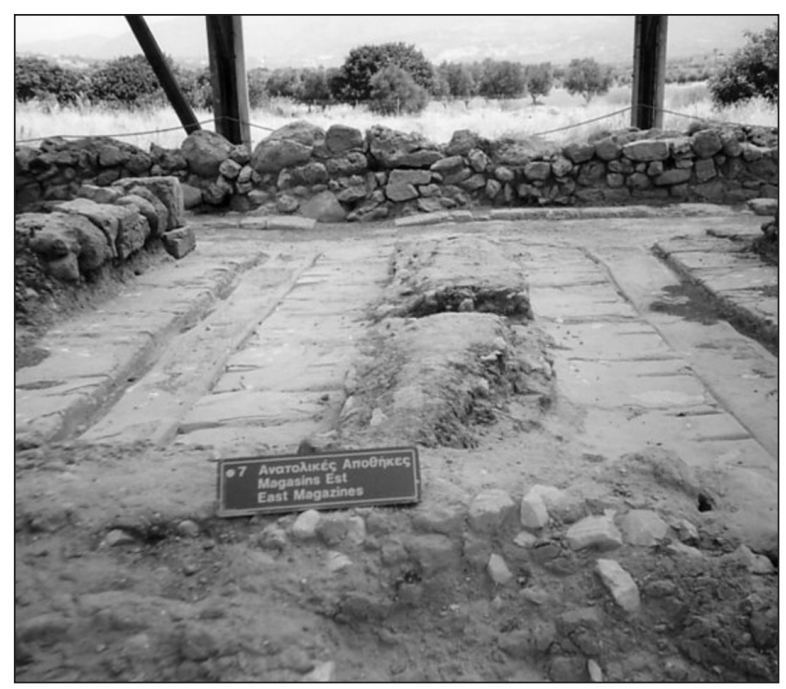

Fig 10.- Detalle de almacenes del Este (foto de la autora)

Fuera del recinto del palacio se encuentran los llamados almacenes Dessenne (ya que fueron excavados en 1960 por A.Dessenne). datados en época protopalacial, están situados a algunos metros del ángulo sudoeste del palacio y en la actualidad se hallan totalmente rellenos.

En el lado Norte del Patio central se localiza otro pórtico de cuyas columnas sólo perviven las basas. Bajo el suelo de este pórtico se han detectado restos de carbón, tierra calcinada y muchas escorias de cobre. Este hallazgo, unido al descubrimiento por parte de Chapoutier en 1928 en este mismo sector de unos moldes para herramientas de bronce del período del Primer palacio, sugiere la probable existencia 
de un taller de broncistas perteneciente a la fase intermedia entre las construcciones protopalaciales y el nivel más reciente (Pelon, 1984:884).

Fuera del palacio, pero muy próximas tenemos dos estructuras de gran interés: la Cripta Hipóstila, al noroeste del palacio, que está constituida por un conjunto de piezas subterráneas, dos metros por debajo de la superficie actual, cuya techumbre de vigas se sostenía mediante columnas. Se fecha en el período protopalacial y es el primer ejemplo en la arquitectura cretense de salas construidas en el subsuelo.

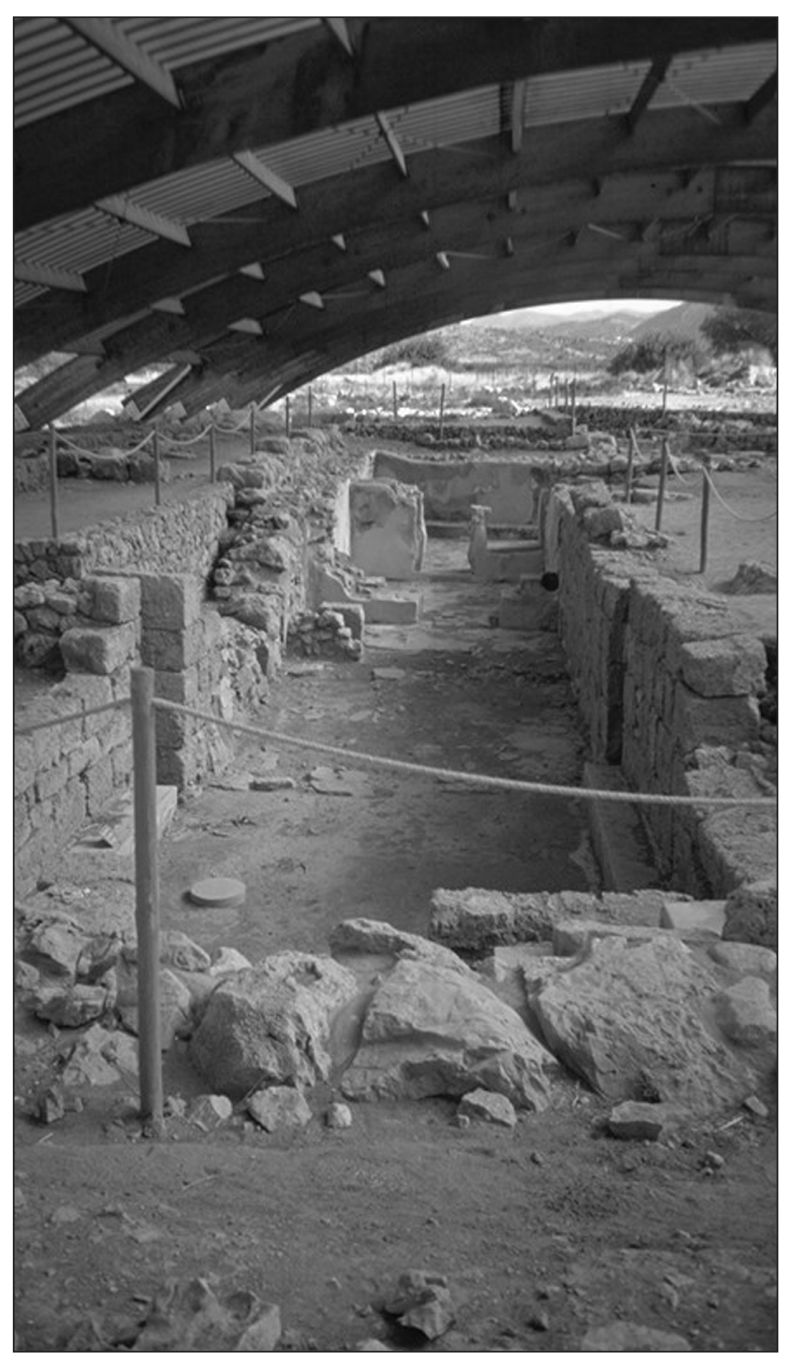

Fig 11.- Cripta Hipóstila (foto de la autora)

A la Cripta se accedía por el lado occidental a través de una escalera acodada que cuenta con doce peldaños. Al norte de ésta, otra pequeña escalinata alcanzaba los pisos superiores. Ambas escaleras daban acceso a una pequeña sala que poseía un banco corrido en tres de sus lados y una columna que sostenía la techumbre. Los restos de un fuste de columna se ha localizado en la prolongación del muro que separa las dos escaleras. Otras tres salas tienen el suelo estucado. La planta superior está compuesta por una serie de cinco almacenes contiguos a la Cripta. Se trata de cinco estancias rectangulares perpendiculares a un vestíbulo con forma de corredor alargado. Dichos almacenes están dotados de canalizaciones y de vasos colectores igual que los que hemos comentado del área Este del Palacio y servía para guardar grandes pithoi. El suelo está estucado y, además, en la zona se ha encontrado una base de columna de mármol azul. La disposición del conjunto y el empleo del estuco de las columnas indica una utilización de tipo oficial quizá de representación. (H. Van Effenterre, 1963: p.47)

El "Ágora" se encuentra situada a unos treinta metros de la puerta Norte del palacio. Se trata de un patio rectangular cercado por unas lajas de ortoestatos de piedra blanca construida en la época de los Primeros palacios. El patio mide cuarenta por treinta metros y es de los más amplios que se conocen en la arquitectura minoica Tiene aspecto monumental y estaba cerrado por sus cuatro lados con grandes bloques de piedra que podrían haber servido de soporte a unas gradas. La superficie de la parte occidental del patio está cubierta por un kalderim de factura grosera que se divide en tres zonas mediante líneas formadas por piedras regulares. Quedan también señales de cuatro bases de columnas de grandes dimensiones con una alineación norte-sur. En este mismo lado occidental algo más al norte el patio parece estar limitado por un pequeño canal destinado al drenaje de la superficie estucada (Van Effenterre,1962:48). Desde las excavaciones de 1960 se dató la zona del Ágora en el período protopalacial. Nuevos sondeos llevados a cabo en las campañas de 1989 y 1990 en la zona al Oeste del Agora (Farnoux, 1990:921) han permitido establecer una estratigrafía fiable que se extiende desde el Minoico Antiguo II A hasta el Minoico Medio I A.

Desde el lado norte a través de una gran puerta cuyo umbral está pavimentado sale un camino en dirección a la necrópolis de Chrisolakkos (de aquí procede la famosa abeja de oro cuidadosamente elaborada). Como se ve, el Ágora y la necrópolis están vinculados por lo que deben ser coetáneas un detalle significativo considerando la escasez de objetos encontrados en la necropólis de esta área. Van Effenterre la ha llamado 'Puerta de las Necrópolis"(Van Effenterre, 1963:49). A partir de esta puerta el muro de ortostatos toma dirección Sur y este lado llama su atención por la semejanza con la fachada palacial. En el ángulo sudeste, un camino lleva dos direcciones, una hacia el patio Oeste y la otra hacia la puerta Norte del Palacio.

No cabe duda de que la Cripta, los almacenes y 


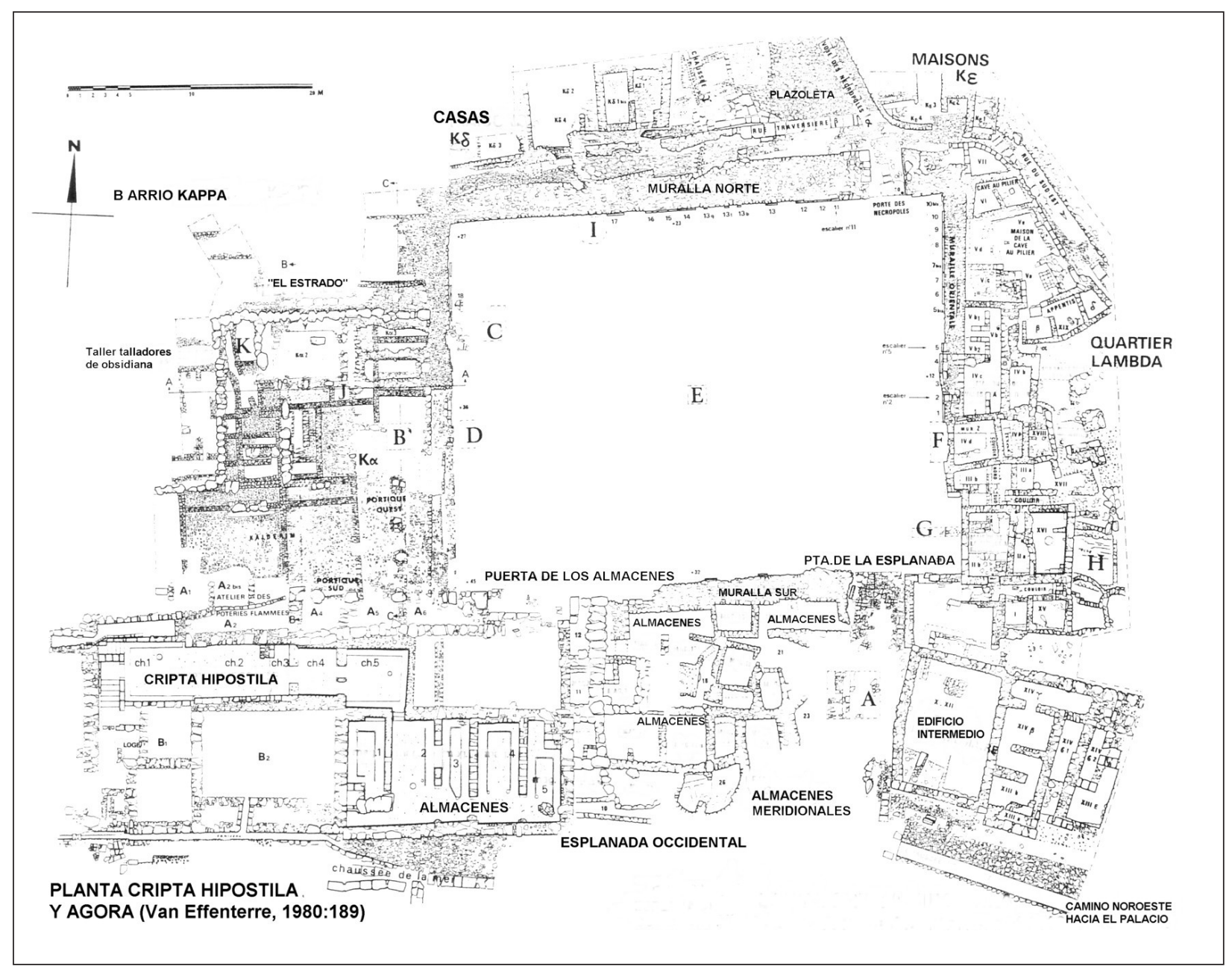

Fig 12.- Planta del Agora y Cripta Hipóstila

el Ágora tienen una relación especial entre ellos. Si en la Cripta se hubiesen encontrado objetos de culto fácilmente se le habría atribuido una función religiosa. Debido a esta ausencia de material de contexto cultual hipotéticamente se ha apuntado una funcionalidad civil y política para todo el conjunto. Las salas con el banco corrido y su anejo de almacenes acogerían un hipotético consejo cuyas reuniones podrían ser interrumpidas por un banquete ofrecido en el mismo lugar, mientras que el Ágora serviría para acoger una eventual Asamblea que ratificaría las decisiones del consejo. Sin calificar esta interpretación de descabellada, hay pocos elementos que corroboren tanto la existencia de un consejo como de una Asamblea en la sociedad palacial del II milenio. Es difícil diferenciar, a la luz de

4 "L'intérêt des découvertes de Malia est donc de mettre désormais en question les conceptions trop autocratique et totalitaire que l'on se faisait de la royauté minoenne. Il est encore trop tôt pour dire si les installations découvertes répondent las evidencias que disponemos, dos tipos de poder político (una monarquía y una organización 'democrática’ o asamblearia) como postula Van Effenterre ${ }^{4}$

Otra zona de gran interés y muy cercana al palacio es el Barrio "Mu". Esta área , por sus peculiaridades es una de las de mayor interés de Malia. El barrio pertenece a la época protopalacial, está situado a unos trescientos metros a poniente del palacio, tiene una extensión de tres mil metros cuadrados, una estructura de características similares al palacio y podría ser un segundo centro de gestión administrativa. Las excavaciones comenzaron en 1965 y continúan en la actualidad (Godart,Olivier, 1978; Detournay, Poursat, 1980,1993; Poursat, 1992; Poursat, 1996; Poursat, Knappett, 2005).

El barrio se compone de dos grandes edificios, A y $\mathrm{B}$, rodeados de siete estructuras de dimensiones

plutôt a un regime aristocratique fondé sur l'acclamation populaire ou á une 'democratie primitive' comparable à celles dont Th.Jacobsen a cru retrouver les traces en Mésopotamie.’(Van Effenterre, 1963:53). 


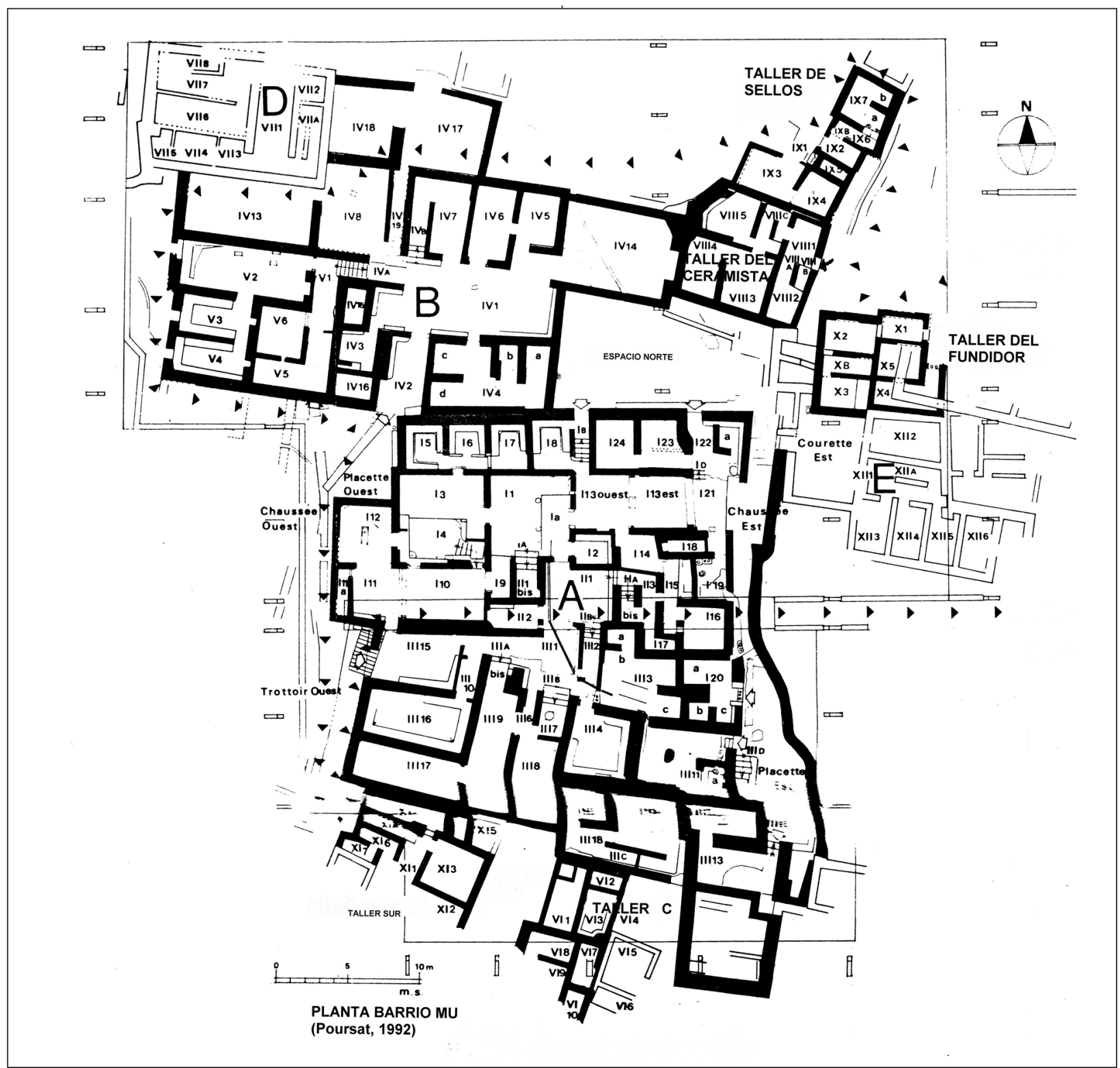

Fig 13.- Planta Barrio Mu

más pequeñas de las que cinco han sido identificadas como casas de artesanos. Estos edificios se construyen a principios del Minoico Medio II (1800) y fueron destruidas por el fuerte incendio del final de este periodo (c.1700) que afectó también al palacio y a otras partes del asentamiento.

El estado de conservación de todo el conjunto es bueno. Los dos edificios principales A y B están construidos con ladrillos de arcilla cruda que fueron arruinados por el incendio y formaron un estrato de destrucción compacto que selló completamente todos los restos haciendo posible el hallazgo de gran cantidad de material (vasos de arcilla, de piedra, utensilios y armas de metal, sellos y documentación de archivos como tablillas e impresiones en arcilla con inscripciones jeroglíficas).
Los dos edificios A y B tienen unas dimensiones poco habituales (840 y $540 \mathrm{~m}^{2}$ respectivamente) y son los únicos, fuera de los palacios de Cnoso y Malia, que nos han proporcionado inscripciones en escritura jeroglífica. Sus características arquitectónicas, innovadoras en muchos aspectos, nos dan una idea de lo que pudieron ser los primeros palacios: patios porticados enlosados, columnas y pilares, estancias con grandes vanos, pozos de luz, sala lustral, sótanos y conjuntos de almacenes. Por otra parte, las casas de artesanos que están alrededor de estos edificios nos dan un testimonio único sobre la actividad y condiciones de vida de los artesanos minoicos de esta época.

El edificio A es el más importante del Barrio $\mathrm{Mu}$ y ocupa $840 \mathrm{~m}^{2}$ de superficie. Tiene una forma tra- 
pezoidal y su lado occidental presenta los entrantes típicos de la arquitectura minoica. La construcción se realizó en dos fases, primero se elevó un edificio rectangular (la mitad norte) al que se le unió un segundo que ocupa toda la parte sur y que incluye el taller Sur y el taller C. El edificio en su conjunto cuenta con salas de representación, almacenes, depósitos de documentos de archivos, una sala de libación, etc. La fachada Oeste, similar a la de los palacios, está construida con bloques tallados de ammouda de 0.60 metros de profundidad por un metro de longitud.

El Edificio B se extiende al noroeste del taller del ceramista y se trata de uno de los edificios más relevantes del conjunto. Tiene una extensión de más de $500 \mathrm{~m}^{2}$ y presenta una arquitectura compleja. En él se han exhumado objetos de representación (aquellos que por la exclusividad del material empleado y su elaborada manufactura se consideran objetos suntuarios) y también dos grandes anclas de piedra de una altura de cincuenta centímetros que probablemente posean una carácter votivo (al igual que se sucede en Oriente para honrar a alguna divinidad del mar, Poursat, 1992:24). Asimismo se han encontrado numerosas cerámicas y una serie de almacenes a donde han caído después de la destrucción, jarras de almacenaje y documentos con inscripciones jeroglíficas. Finalmente, el subsuelo del Edificio B ocupa una superficie de cien metros cuadrados y está construido sobre un lecho de roca cuidadosamente tallado y proporciona interesantes datos sobre las técnicas de construcción minoicas (altura de los muros, huecos de apoyo de las vigas, marcas de las vigas de madera horizontales, marcos de puertas y ventanas y nichos).

En la parte septentrional del Barrio $\mathrm{Mu}$ se encuentran los talleres de artesanos: broncista, ceramista y grabador de sellos. Los artesanos residían en esas casas con sus familias y dependían de los residentes de los edificios cercanos A y B. En cada casa, una de las habitaciones constituía el lugar de trabajo del artesano.

En definitiva, no sólo las dimensiones de estos dos edificios sobrepasan las habituales de otras casas minoicas sino que las funciones que se han visto reflejadas por los hallazgos son similares a las palaciales. De este modo, tenemos evidencias de estancias de carácter religioso, de representación, administrativas, de almacenamiento y de talleres agrupados en una especie de 'área artesanal'. Ciertamente no contamos con datos suficientes para saber el vínculo de esta área con el palacio y resulta difícil determinar la relación de este recinto con el palacio y la posición de las personas que en él habitaban, sin embargo, sin duda muestra una organiza- ción urbana compleja fuera de la estructura palacial.

\section{Conclusiones}

Podríamos definir al estado como entidad política jerárquicamente organizada y centralizada que controla un determinado territorio y que se reconoce por la existencia de una serie de instituciones diferenciadas y por la existencia de un sistema social jerarquizado en función del estatus jurídico, el nacimiento, el sexo, la edad, la especialización laboral y la riqueza con un acceso diferenciado a los recursos básicos (Service, 1962; Adams, 1966; Fried, 1967; Flannery 1972 ) .

La organización estatal supone así, una profunda transformación de las sociedades humanas, un incremento de la complejidad de las diferentes relaciones políticas, económicas y sociales que dan lugar a un proceso de urbanización cuyas características principales son: una población numerosa y densa, un alto nivel de complejidad y de interdependencia, una organización formal e impersonal, importantes actividades no agrícolas y unos servicios centrales diversificados(Redman, 1990:278). En el caso cretense conlleva, en suma, la aparición de una arquitectura monumental y palacial, una expansión demográfica con un incremento notable de asentamientos, nuevas prácticas rituales de enterramiento, hábitats más grandes y más complejos, novedades en la cerámica (especialización y estandarización), importantes avances en la artesanía metalífera, sobre todo en orfebrería, y la aparición de la glíptica, especialmente, una mayor estratificación social y relaciones comerciales de largo alcance.

El rasgo más característico de los comienzos del bronce Medio es la aparición de unas estructuras monumentales características que en su día Evans denominó palacios, que van acompañadas de importantes cambios en las estructuras económicas y sociales de la sociedad cretense y que, a nuestro juicio, constituyen prueba suficiente de la existencia de un entro político estatal. La arquitectura palacial supone de alguna manera imperfectamente conocida la existencia de un poder centralizado, con una figura principal que sería el 'señor del palacio', el rey, o el rey-sacerdote si consideramos que la base de la organización política del palacio tiene una estrecha relación con la vida religiosa similar a los palacios mesopotámicos. A través de la iconografía de frescos y sellos (de época neopalacial) se ha querido ver también la presencia de un príncipe o del rey (interpretación de Evans del Príncipe de los Lirios o el llamado Vaso de los Chieftains, con sus detractores (Davis, 1995):11-19) y defensores (Marinatos, 
1995:37-47)). Incluso el Salón del Trono del palacio de Cnoso, que ha venido siendo considerado como el trono del rey (Reusch, 1987: 163-168). En realidad, como afirma Koehl (Koehl, 1995: 23-35), es difícil diferenciar por la iconografía los inmortales de los mortales, la divinidad de la realeza o el noble del rey y no parece posible asegurar una interpretación iconográfica con cierto grado de certidumbre sin apoyarse en otras evidencias. Ciertamente, con la información que disponemos en la actualidad y, sobre todo, al no poder descifrar la documentación escrita, es difícil llegar a definir con claridad la figura del dirigente en la sociedad minoica y más aún en el período que nos ocupa. Podría tratarse de un rey o de un primus inter pares, y también podría existir una dualidad de poder entre el rey y la reina en la que esta última ejerza también funciones religiosas e incluso (por las características de la iconografía) pueda llegar a representar a la divinidad. También es posible, como afirma Marinatos, que la autoridad de estos dirigentes frente a su comunidad hubiese sido adquirida a través d e su carácter divino o por su facultad de intermediar entre ésta y la divinidad. Platón considera que la interpretación de los diferentes elementos comunes de los cuatro palacios (Cnoso, Festo, Malia y Zakros) y de otros edificios relevantes minoicos no sólo justifica sino que refuerza los presupuestos de Evans sobre la organización teocrática de la sociedad minoica ${ }^{5}$.Sin embargo, podemos afirmar, con total seguridad, la existencia de una organización estatal y de uno o varios dirigentes, con funciones políticas y religiosas similares a las del rey-sacerdote en la civilización mesopotámica. En conjunto, todas las construcciones complejas y no sólo el palacio, como prueba el caso de Malia, responden a las necesidades complejas de unos dirigentes que son los que organizan la vida social. La transformación del hábitat, de las necrópolis y de las prácticas funerarias nos permite deducir que los antiguos clanes o bandas están desmembrados y el surgimiento de una serie de instituciones, una nueva estratificación caracterizada por el desarrollo de una especialización laboral y una serie de personas adscritas directamente a la organización estatal: altos funcionarios palaciales, sacerdotes, sacerdotisas, artesanos, mercaderes y marinos, agricultores y ganaderos.

En los inicios del Bronce Medio se produce un crecimiento demográfico, aparecen nuevos asentamientos y se incrementa el tamaño de los ya conocidos. Se produce también una cierta diferenciación regional que permite entrever que no todos los procesos se producen en el mismo momento en la isla, de hecho, en el período de los 'Primeros Palacios' tenemos atestiguados únicamente tres estructuras monumentales principales, los palacios de Cnoso en la zona norte del centro de la isla, Malia, también en la zona norte pero más hacia el oriente y Festo al sur de la zona central. Sobre esta base, ya desde época protopalacial se ha querido también distinguir una división territorial de la isla en varios hipotéticos

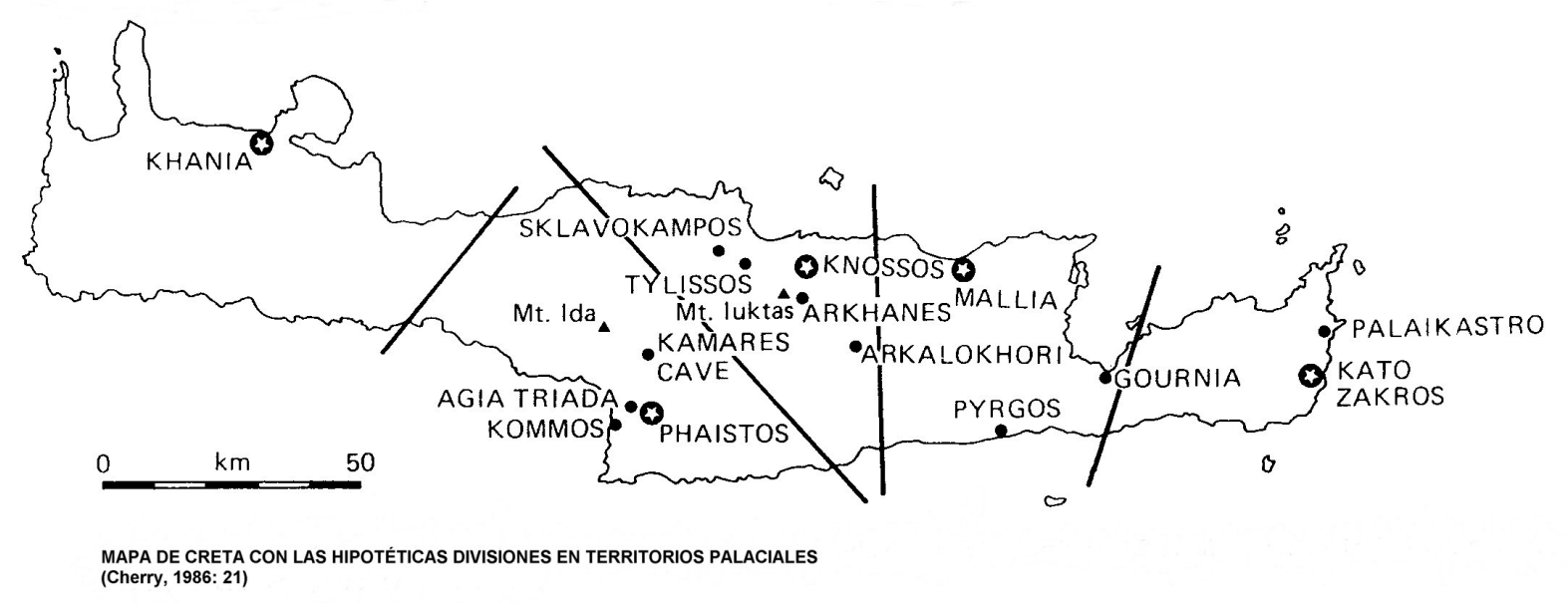

Fig 14.- Mapa de Creta, divisiones territoriales

5 "..the organization of the social and political system in Minoan Crete was theocratic and that the importance of the priesthood found expression in the members of the royal family, who as a divine genos were blood-relations to the deity. Life was organised on a theocratic basis; and this explains the miracle whereby any abuse of power was avoided, the miracle of peaceful co-existence --Pax Minoica. The kings of Crete, having acknowledge the king of Knossos as'primus inter pares', lived in harmony among themselves" en Platon, 1983:276. 
reinos cada uno correspondiente al territorio controlado por cada uno de los tres palacios principales, Cnoso, Malia y Festo. Ciertamente los estilos cerámicos se corresponden bastante bien con esta pretendida división política y administrativa pero el hecho de que no dispongamos de textos descifrables, la aparición de nuevos centros (Galatas, Monastiraki, Patras) y la existencia de ciudades de tipo secundario como Gurnia, Palaikastro o Pyrgos, pueden hacer tambalearse esta hipótesis y han provocado una continua revisión de los estudios sobre la civilización minoica ( Driessen, Shoep y Laffineur, 2002). Con todo, parece indudable la existencia de una jerarquización de asentamientos que apuntan a una articulación territorial del territorio característica de una organización estatalizada y la distinción de grupos regionales en la producción se corresponde con bastante exactitud a una hipotética realidad administrativa y política (Poursat,1992: 140)

Este mismo desarrollo de una civilización más compleja también se constata por la concentración de objetos de lujo en palacios y por la aparición de artesanos especializados (por ejemplo en el Barrio $\mathrm{Mu}$ el descubrimiento de la espada de pomo de cristal de roca; las dos espadas de lujo encontradas en el palacio de Malia , una de ellas la del 'acróbata' en el Sector III y el puñal con mango incrustado recubierto de oro). En este contexto de transformación social es significativa la aparición desde inicios del MMI de nuevas formas de sepultura en las proximidades de nuevas aglomeraciones que también constituyen indicios de diferenciación social. En Creta oriental y Central aparecen sarcófagos en forma de cofre redondeado y podemos intuir una oposición entre tumbas colectivas (a veces ricas en materiales) y las necrópolis ordinarias de inhumaciones en jarra (pithoi) o en sarcófagos, todas ellas con ajuares pobres.

En la época de los primeros palacios se produce un incremento notable de la producción artesanal y el gran avance se produce en el trabajo del metal así como en otros tipos de artesanía de la piedra como obsidiana, mármol y el marfil. La cerámica de Camares se produce en grandes cantidades y hay una cierta estandarización en el diseño y la forma. Los llamados 'almacenes de carpintero' aparecen en este momento ( Poursat, 1992:149) y en ellos se han encontrado dobles hachas, azuelas, tijeras, sierras, taladros tubulares (para la elaboración de sellos). La utilización de herramientas de metal favorece el desarrollo de la industria artesanal (madera, piedra,

6 Probablemente, la fabricación de la espada minoica tiene relación con los contactos con Byblos durante el MM I- cuero etc..). El bronce es un punto principal de la actividad manufacturera minoica a pesar de que la materia prima para su fabricación debía ser importada. En el MM II los cretenses habían desarrollado una larga serie de herramientas de metal, habían inventado la espada larga ${ }^{6}$, fabricaban unas excelentes figurillas de bronce y habían desarrollado la industria de los vasos de metal (Betancourt, 1998: 8). Las excavaciones en Chrysokamino (Este de Creta) han evidenciado que allí se estaba produciendo cobre en el MA III . Se trata de un asentamiento de inicios del período protopalacial justo antes de los principales contactos entre Creta y el norte de Siria (Betancourt, 2006).

Si bien algunos investigadores rechazan la existencia de una centralización de la economía valiéndose de la aparición en el Barrio Mu de Malia de archivos contables, en edificios separados del palacio que supondría la existencia de ámbitos diferentes, cada uno con su propia contabilidad, lo que es cierto es que en estos momentos en Creta hay un sistema de control económico que se demuestra por los documentos escritos y los precintos de arcilla marcados con huellas de sello descubiertos en Cnoso (depósito jeroglífico), en Festos (depósitos con huellas bajo la sala XXV), Malia (Barrio Mu) e incluso en centros no palaciales como es el caso de Monastiraki. Tenemos evidencias de archivos contables e incluso un sistema que podría ser utilizado para contabilizar las salidas y entradas de mercancías al igual que se documenta por ejemplo en Mesopotamia. La existencia de un sistema burocrático está demostrada por la aparición de nódulos de arcilla, precintos de puertas y de tinajas, barras de arcilla inscritas, huellas de sellos, sellos y tablillas inscritas. Los sellos de arcilla precintaban pequeñas cajas, puertas, pequeños recipientes. Las barras y bolas de arcilla sellaban contenedores que podrían servir para guardar archivos en material perecedero (papiro, pergamino u hojas de palmera) (Platon, 1981:286). Se trata de una administración que lleva a cabo un control económico.

La propia situación geográfica de la isla es quizás uno de los principales condicionantes para explicar los procesos evolutivos que en ella se han dado y no puede ser en modo alguno desdeñada. Creta es la isla griega de mayor tamaño con una extensión aproximada de ocho mil kilometros cuadrados y constituye el extremo más meridional del Mar Egeo. La isla forma parte del arco sur que cierra dicho mar y que comprende, al oeste las islas de Anticitera y

MMII. Los tres remaches típicos de estas piezas se asemejan a los que se fabrican en Byblos. Ver K. Branigan, 1967 


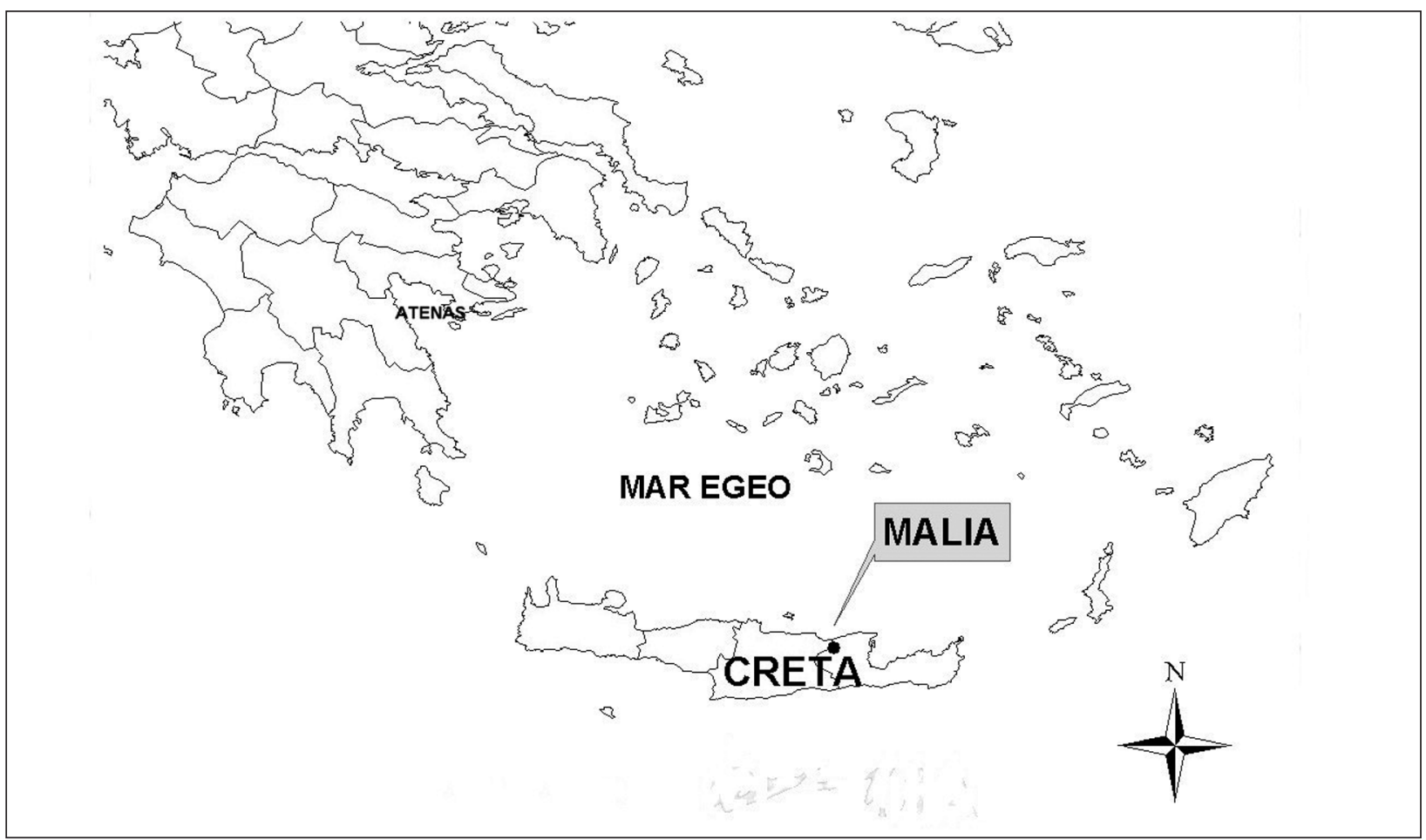

Fig 15.- Mapa de Grecia y Egeo (elaboración propia)

Citera, hasta las costas peloponesias, $\mathrm{y}$, por el este, las islas del Dodecaneso, Cárpato y Rodas, hasta el litoral de Anatolia. Su silueta característica y sus accidentadas costas siempre han servido de referencia para los navegantes. La isla tiene una longitud de unos doscientos cincuenta kilómetros. La parte más ancha va desde el cabo Stravos, al oeste de Candía, hasta el Cabo Kefala, el antiguo Cabo León, es decir unos cincuenta y siete kilómetros. El istmo de Ierapetra , sin embargo sólo posee doce kilómetros de ancho, y el istmo de Retimno, dieciocho kilómetros. . Creta posee, pues, una posición geográfica estratégica, a medio camino entre la costa de Anatolia y el continente griego y cercana a las costas del Levante y de Egipto. Sin duda este fue uno los puntos cruciales para el desarrollo que experimentó la isla ya desde el Minoico Antiguo (Ca.3000) o período Prepalacial. Es en este período cuando ya se anticipa el gran cambio que se produ-

7 Wiener, 1987,261-7

8 "Evidence of Minoan trade outside the Aegean first appears in MM IA. The earliest object is the famous MM IA jar found in Tomb 806 at Lapithois in northern Cyprus. MM IB-II pottery, mostly cups, has been found at Karmi on Cyprus, and in Syria-Palestine at Ugarit, Qatna, Beirtu and Byblos. Kemp and Merrillees have studied Minoan imports in Egypt . MMIBI-II sherds are known from Lisht, Harageh, Kahun, Abydos, and Qubbet el-Hawa near Aswan. The contexts of cirá mas adelante con importantes transformaciones en relación con la fase del Neolítico.

Creta era deficitaria en materias primas que los minoicos buscaban en los puertos del Levante y de Egipto; plata, cobre, estaño, metal y piedras preciosas a cambio de madera y productos manufacturados como textiles, vasos de metal, armas y cerámica. Poseemos evidencias de contactos con el Oriente Próximo ya desde el MA y con la costa de Anatolia y las islas (Rodas y Cos) en el MM II. Asimismo ha aparecido cerámica minoica en Casos, Cárpatos, Saria, Chalki, Kalimnos, Telos, Nisiro, Astipalea y Samos (Wiener, 1987:5, notas 1 y 2) y en Anatolia en Mileto, Iaso y Cnido. Vasos de Camares aparecen en Chipre, Ugarit donde existen, incluso, imitaciones de cerámica de Camares $^{7}$, Biblos y Egipto ${ }^{8}$. Es probable que los vasos minoicos del norte de Chipre nos estén indicando una posible ruta entre Creta y Sirio-Cilicia . La cerámica de Camares se documen-

these vases in Egypt range from the $12^{\text {th }}$ to the $13^{\text {th }}$ Dynasties. Knossian and Phaistian potters also made for export clay vases in imitation of foreign metal vases. Warren \& Hankey have argued that the silver vases on the Tôd Treasure which probably date to the $12^{\text {th }}$ Dynasty, are Minoan (or can be taken as evidence of similar Minoan work).” ( Wartrous 2001: 211). 
ta también a lo largo de la costa Siria y Palestina . Por último, en documentos del archivo de Mari se cita a Creta y Ugarit ${ }^{9}$, el documento de Mari se cita Creta y Ugarit. Como explica Wiener (Wiener, 1987:262), el Bronce Medio fue una época de expansión del comercio internacional en la zona que va desde Anatolia, hasta la costa de Siria y Palestina y Egipto. La ciudad de Mari, debido a su situación estratégica en el paso de importantes rutas, desempeñó un papel primordial como centro de distribución del comercio internacional y, como revelan los archivos, constituía el principal proveedor de estaño procedente de oriente para los países situados más al Este (Kuhrt, 2000: 123). El estaño llegaba a Mari desde Irán y podía remitirse a otros lugares como Alepo, Hazor y Ugarit, donde se mencionan mercaderes de estaño. En la documentación de Mari se hace referencia al estaño destinado a un hombre de Kaptara y a un interprete residente en Ugarit. La existencia de un interprete implica la existencia de un comercio regular (Wiener, 1987: 262). Si como se cree, Kaptara corresponde a la denominación de Creta $^{10}$, está clara la conexión de la isla dentro del circuito comercial existente en el PO. Igualmente se hace referencia a un arma de metal con incrustaciones kaptaritas y a un envío de mercancías a Kaptara por parte de Zimri-Lim a Hammurabi de Babilonia (que quizás podría ser un ejemplo de intercambio de regalos).

Todas estas pruebas arqueológicas señalan que el comercio minoico con el Este se inició en el Bronce Medio I (MMI-II) y que no se limitó al intercambio de productos sino de técnicas e ideas que los minoicos pudieron tomar de los egipcios y orientales y de sus palacios ${ }^{11}$.

Ciertamente es difícil demostrar que los primeros palacios regulaban totalmente el comercio exterior. De las funciones económicas señaladas, las más claras y mejor documentadas son la de centros de

9 One Mari tablet (A 1270) records over $500 \mathrm{~kg}$. Of tin in the palace inventory, or enough for 7-10,000 kg. of bronze. The tablet shows that the tin came to Mari from the direction of Iran and went to many palaces including Aleppo, Hazor and Ugarit where two resident and probably Mariote tin merchants are mentioned. If "Kaptara" was indeed Crete, then the connection of Crete to his tin route is established by a reference in the same text to tin destined for a man from Kaptara and an interpeter resident in Ugarit (who is to be paid in for his services). The Mari tablets also refer to a Kaptarite inlaid metal weapon, and to Zimri-Lim sending goods from Kaptara to Hammurabi of Babylon -an example , perhaps , of palatial gift exchange.." (Wiener, 1987:262).

10 "The identity of Kaphtor has been accepted as Crete, based on the appearance and attributes of the Keftiu in New almacenamiento y de distribución dentro del propio territorio. El palacio es la sede de una economía centralizada (Van Effenterre, 1987:180), centro de producción artesanal donde se fabrican diferentes manufacturas (bronces, cerámicas, vasos de piedra, tejidos, armas, etc.) y también podríamos afirmar que cumple una determinada función comercial como lo demuestra los objetos que en ellos han aparecido (colmillos de elefante en Zakros, objetos egipcios en Cnoso) y que importa materias primas (estaño, cobre, etc). Si bien no se puede negar la existencia de la actividad comercial individual parece poco viable que un comercio a larga distancia y sobre todo de metal y objetos de prestigio pudiera llevarse a cabo sin el apoyo y sin los recursos que puede proporcionar la organización palacial. Sin duda el comercio y la importación de metal era una necesidad primaria para la organización palacial (herramientas, armas, objetos de prestigio y de culto) y, por lo tanto, el mantenimiento de relaciones comerciales exteriores con el fin de asegurar aprovisionamientos de metal tuvo que ser un objetivo primario para la sociedad palacial. Por todo ello se puede afirmar que en el período protopalacial los movimientos de mercancías formasen parte de una actividades en cierto modo dirigida y controlada en gran parte por el palacio aunque no debemos descartar-como sucede en el Oriente-la existencia de iniciativas mercantiles individuales.

Sabemos, además, de la existencia de una marina minoica por las representaciones de barcos de vela y remos en sellos y maquetas. Los modelos en arcilla muestran una proa alta mientras que la popa es baja y con una especie de espigón atrás. Los barcos tenían dos o tres velas y varias líneas de remos. Los barcos grandes transportaban mercancías y no hay evidencias de la existencia de barcos para el combate (o bien no existía tal a diferenciación). También se han encontrado anclas de piedra que,

Kingdom tomb paintings and Near Eastern references, which extend from the third millennium B.C. through the third century A.D. As early as the reign of Zimrilim (ca.1780) at Mari on the Euphrates, merchants from "Kaptar" acquired tin from the Near East and apparently turned it into weapons (described as 'kaptarite work') inlaid with precious materials like gold and lapis lazuli". (Morris, 1992: 94).

11 "Egiptian palaces and Near East ones like those of Mari, Alalakh and, most recently Kabri (on Israel's northernmost coast, sourthern Phoenicia of later days) with their large coutyards and fresco paintings were suggested as a source of inspiration for the Minoan palaces” (Kochavi 1992: 7-15). 
aunque pudieran tener un significado votivo, reflejarían también su utilización en la navegación.

Como vemos, en los Primeros Palacios, todavía a nivel reducido, se evidencian ya las cinco funciones económicas que en la época de los segundos palacios claramente cumplirá la estructura palacial: producción, almacenamiento, consumo, regulador del intercambio interno y regulador del comercio externo ; de ello tenemos evidencias en los palacios de Cnoso, Festo y Malia (Branigan 1987:245-249).

En el contexto del nacimiento del Estado en la Creta protopalacial, el asentamiento de Malia constituye uno de los mejores ejemplos de lo que pudo ser el centro político d eun estado minoico en la primera mitad del segundo milenio. Se compone de un conjunto de edificios con grandes similitudes arquitectónicas y con funciones complementarias de gran utilidad para analizar con mayor certidumbre los rasgos de la sociedad minoica del período. En el palacio, residencia oficial del gobernante, podemos observar las zonas de representación o de aparato así como algunas actividades económicas que evidencian la práctica de una economía de tipo redistributivo y también determinadas funciones cultuales y religiosas. Fuera del palacio, y sobre todo en el Barrio $\mathrm{Mu}$, tenemos claros ejemplos de una producción artesanal altamente especializada, probablemente relacionada con el palacio y de la existencia de un sistema administrativo de registro y control de la producción. Como hemos visto, este proceso se gesta a consecuencia de un incremento demográfico considerable que trae consigo unas concentraciones de población y un incremento de asentamientos, una situación geográfica peculiar que favorece una serie de contactos con el exterior que sin duda alguna ejercen una gran influencia en las elites que están surgiendo en la isla produciendo la emulación en ciertos aspectos, de las estructuras de sociedades mas desarrolladas. Al proceso cretense se le podrían aplicar tanto una parte de las teorías de conflicto como de las de integración en tanto que un incremento demográfico trae consigo una competencia por unos recursos escasos que produce consigo la adaptación hacia un sistema de producción agrícola diversificado (policultivo mediterréno) que da lugar a la aparición de un grupo dirigente capaz de liderar el paso hacia una organización de tipo estatal centralizada alimentado por el conocimiento de las instituciones y aparatos estatales de Oriente Próximo, que da lugar a un cambio social de tipo endógeno y exógeno al mismo tiempo.

En definitiva, a pesar de no haberse descifrado la documentación escrita (tablillas en escritura jeroglífica y en Lineal A), las estructuras arquitectónicas y los restos de la cultura material nos desvelan estruc- turas sociales, políticas y económicas que se ajustan perfectamente a las características de la existencia de organización estatal y nos permiten por tanto afirmar que estamos ante la primera organización estatal que surgió en el Egeo y en Europa .

\section{Bibliografía}

ADAMS, R.McM (1966): The Evolution of Urban Society: Early Mesopotamia and Prehispanic Mexico. Chicago; Aldine.

BETANCOURT, Ph.P. (1998): "Middle Minoan objects in the Near East", Proceedings of the Fifth Anniversary Symposium: The Aegean and the Orient in the second millennium, 1997, AEGAEUM 18, 5-11.

- (2006): "The Chysokamino Metallurgy Workshop and its Territory. Hesperia, supl. 36.

BRANIGAN, K. (1967): "Further Light on Prehistoric Relations between Crete and Byblos", AJA 71, 117121.

- (1987): "The Economic Role of the First Palaces" en R.Hägg and N.Marinatos (eds), Proceedings of the Fourth ${ }^{h}$ International Symposium at the Swedish Institute in Athens: The Function of the Minoan Palaces, R. Hägg and N. Marinatos eds., Stockholm, 1984, 245-248.

CADOGAN, G. (1976): Palaces of Minoan Crete, Londres, Nueva York.

CARNEIRO, R., (1970): "A theory of the Origin of the State”. Science 169 (1947):733-738.

COHEN, R., SERVICE, E.R. (1978) .Origins of the State, the Antropology of Political Evolution. Institute for the Study of Human Issues. Philadephia.

CHERRY,J.F. (1986): "Polities and Palaces: Some Problems in Minoan State Formation", Peer Polity Interaction and Socio-Political Change, $C$. Renfrew and J. F. Cherry eds., Cambridge, 19-45.

CHILDE, G. (1948). Man makes himself. Londres.

(1950) “The Urban Revolution". Town Planning Review 21 (1):3-17. Routledge and Kegan Paul. London.

DAVIS, E. (1995): "Art and Politics in the Aegean: the Missing Ruler" en The role of the ruler in the Prehistoric Aegean, AEGAEUM 11, P. Rehak ed., Lieja-Austin. 11-19.

DETOURNAY, B. \& POURSAT, J.C. (1980):"Le Quartier Mu 2: Vases de pierre et de metal, vannerie, figurines et refliefs d'applique, élements de parure et de décoration, armes, sceaux et 
empreintes". Études Cretoises, vol. 26. Paris. École Francaise d'Athènes. Athènes.

DICKINSON, O.P.T. (1994): The Aegean Bronze Age, Cambridge.

DRIESSEN, J., SHOEP, I., LAFFINEUR, R.(eds.).(2002): MONUMENTS OF MINOS. Rethinking the Minoan Palaces. Proceedings fo the International Workshop "Crete of the hundred Palaces?" . Université Catholique de Louvain, Louvain-la Neuve, 14-15 December 2001, AEGAEUM 23. Liége.

ENGELS, F. (1884). El Origen de la familia, de la propiedad privada y del Estado. Reedición 1970. Madrid.

FARNOUX, A. (1990). “Travaux de L'Ecole Française en Gréce en 1989". Malia.Sondages autour de la Crypte Hypostyle. $B C H$ 114. p. 921

FLANNERY, K.V. (1966): "Social and Economic Systems in Formative Mesoamerica" en S.R.Bindford y L.R.Bindford (eds). New Perspectives in Archaeology. Chicago

FRIED, M.H. (1967): The Evolution of Political Society. Random House. New York

GARCÍA IGLESIAS, L. (1997): Los orígenes del pueblo griego. Madrid

GODART, L. ET OLIVIER, J.P. (1978): "Malia. Le Quartier $\mathrm{Mu}$ I. Introduction genérale para J.Cl.Poursat. Écriture hiéroglyphique crétoise par L.Godart et J.P.Olivier”.Etudes Crétoises, vol. 23. École Francaise d'Athènes, Athènes.

HALSTEAD, P. (1981): "From Determinism to Uncertainty: Social Storage and the Rise of the Minoan Palace", Economic Archaeology, A.Sheridan and G.Bailey eds., Oxford, 187-213.

HALSTEAD, P. AND J.O'SHEA (1982) "A Friend in Need is a Friend Indeed: Social Storagwe and the Origins of Social Ranking", in C.Renfrew and S.Shennan (eds.), Ranking, Resource and Exchange , Cambridge, 92-99.

KOEHL, R. B. (1995): "The nature of Minoan Kinship", The Role of the Ruler in the Prehistoric Aegean, AEGAEUM 11. Lieja-Austin, 23-35.

KUHRT, A. (2000) : El Oriente Próximo en la Antigüedad, I c. 3000-330 a.C. Barcelona.

LIVERANI, M. (1998). Uruk, la prima cittá. Editori Laterza. Roma

MARINATOS, N.(1995): "Divine Kingship in Minoan Crete", The Role of the Ruler in the Prehistoric Aegean, AEGAEUM 11. Lieja-Austin, 37
MORRIS, S.P. (1992): Daidalos and the origins of Greek Civilisation. Princetown

O'SHEA, j. (1981): "Coping with scarcity: exchange and social storage" en Economic Archaeology. BAR International Series 96.Oxford.

PELON , O. (1982) : « L'Épee à l'acrobate et la chronologie maliote » en $B C H N^{\circ} 106,165-190$.

- (1983): «L'Épee à l'acrobate et la chronologie maliote II » en $B C H \quad 107,679-703$

- (1984).“Travaux de L'Ecole Française en Grèce en 1983. Malia”.BCH 108. 881-891

- $\quad$ (1986a). “Travaux de l'Ecole Française en Gréce en 1985". BCH 110, 814.-822

- (1986b): "Un dèpôt de fondation au palais de Malia". BCH 110. 3-19.

- (1992): Guide de Malia. LE PALAIS et la Nécropole de Chrysolakkos. École Française d'Athènes

- (1999): "Malia. Le Palais". BCH 123. pp.468-481.

PLATON, N. (1981): La civilisation égéenne, 2 vols. Éditions Albin Michel. Paris.

- (1983): “The Minoan Palaces: Centres of Organization of a Theocratic Social and Political System" en Minoan Palaces. Proceedings of the Cambridge Colloquium 1981. Ed. Krzyszkowska \& L.Nixon. Bristol. 273-276.

POURSAT, J. C. (ed.) (1992): Guide de Malia au temps des premiers palais, Le Quartier Mu. Ècole Française d'Athenes. Atenas.

- (1992): "El bronce medio en Creta" en TREUIL, R. et alii (1992), 129-157

- (1996): "Fouilles exécuées à Malia: le Quartier Mu III: Artisans minoens: les maisons-ateliers du quartier Mu", Etudes Crétoises 32. Ècole Française d'Athenes. Atenas.

POURSAT, j.e., KNAPPETT, C, (2005): Le QuartierMu III. Ld poterie du Minoem Moyen II. Production et utilisation”, Etudes Crétoises 33.

REDMAN, C.L. (1990). Los orígenes de la Civilización. Desde los primeros agricultores hasta la sociedad urbana en el Próximo Oriente. Barcelona.

RENFREW, C. (1972): The emergence of Civilisation. The Cyclades and the Aegean in the Third Millennium B.C., Londres.

RENFREW, C. \& CHERRY,J.F. (1986): Peer Polity Interaction and Socio-Political Change, C. Renfrew and J. F. Cherry eds., Cambridge.

REUSCH, H. (1987): "On the function of the 'Throne 
Room' in the Palace at Knossos”, en N.Hägg \& N.Marinatos , The Function of Minoan Palaces, 163-168..

SERVICE,E.R. (1962) Primitive Social Organization: An Evolutionary Perspective, $2^{a}$ ed., 1971: Nueva York:Randon House.

- (1978)."Classical and Modern Theories of the Origins of Government", en Origins of the State , the Anthropology of Political Evolution. Institute for the Study of Human Issues, Philadelphia :21-34.

(1990). Los orígenes del Estado y de la civilización. Madrid ( ${ }^{\mathrm{a}}$ ed. 1975)

SHERRAT A.G. ,(1981): "Plough and pastoralism: aspects of the secondary products revolution" en Hodder et alli. Pattern of the past. Cambridge, 261305

TREUIL, R. et alii. (1992): Las civilizaciones egeas. Del Neolítico a la Edad del Bronce, Barcelona.

VAN EFFENTERRE, H. (1963): "Politique et religion dans la Crète Minoeene" Cretica selecta. 1 Minoica, Amsterdam, 1990.

- (1980): Le Palais de Mallia et la Cité Minoenne. Étude de synthèse, I-II. Roma.

- (1982): “Peut-on dater les épées de Mallia?”. BCH 106, 163-164.

- (1987)"Les functions palatiales dans la Crete minoenne", Actes du Colloque sur "le système palatial »(Strasbourg, 19-22 juin 1985), éd.E.Lévy. 173-184.

- (1990) "Mallia”, Cretica selecta. 1 Minoica, Amsterdam, 187.

WATROUS, L. V. (1987): "The Role of the Near East in the Rise of the Cretan Palaces", Proceedings of the Fourth International Symposium of the Swedish Institute: The Function of Minoan Palaces, Atenas, 1984, R. Hägg and N. Marinatos eds., 65-70.

- $\quad$ (1994): "Crete from Earliest Prehistory through the Protopalatial period. Addendum: 1994-1999" en Aegean Prehistory. A review AJA, supl. I., 157-223.

WIENER, M. (1987): "Trade and Rule in Palatial Crete", Proceedings of the Fourth International Symposium of the Swedish Institute: The Function of Minoan Palaces, Atenas, 1984, R. Hägg and N. Marinatos eds., 261-267.

WILSON, J.A.,(1953):La cultura egipcia. Breviarios F.C.E. México

WITTFOGEL, K.A., (1957): Oriental Despotism: A comparative Study of Total Power. Yale University Press. New Haven, Conneticut.

WRIGHT, H.T. (1978): "Toward an Explanation of the Origin of the State", en Origins of the State, the Antropology of Political Evolution, Cohen \& Service: 49-68. 